\title{
A Robust Data-driven Macro-socioeconomic-energy Model
}

\author{
Simon H. Roberts ${ }^{\mathrm{a} *}$, Colin J. Axon ${ }^{\mathrm{b}}$, Barney D. Foran ${ }^{\mathrm{c}}$, Nigel H. Goddard ${ }^{\mathrm{d}}$, and Benjamin S. Warr ${ }^{\mathrm{e}}$. \\ ${ }^{a}$ Arup, 13 Fitzroy Street, London W1T 4BQ, UK. Simon.Roberts@arup.com \\ b Institute of Energy Futures, Brunel University, Uxbridge, London UB8 3PH, UK. \\ Colin.Axon@Brunel.ac.uk \\ ${ }^{c}$ Institute of Land Water and Society, Charles Sturt University, PO Box 789, Albury, NSW 2640, Australia. \\ Barney.Foran@gmail.com \\ d School of Informatics, University of Edinburgh, 10 Crichton Street, Edinburgh EH8 9AB, Scotland. \\ Nigel.Goddard@ed.ac.uk \\ ${ }^{\mathrm{e}}$ Executive in Residence, INSEAD Social Innovation Center, Europe Campus, Boulevard de Constance, \\ 77305 Fontainebleau, France. Benjamin.Warr@insead.edu \\ * Corresponding author.
}

\begin{abstract}
In a resource-constrained world with growing population and demand for energy, goods, and services with commensurate environmental impacts, we need to understand how these trends relate to aspects of economic activity. We present a computational model that links energy demand through to final economic consumption, illustrated by application to UK data. Our model fits within a whole-economy framework which harmonises multiple national accounting procedures. Our model minimises both the number of exogenous aspects and tuning factors by using historical data to calibrate relationships. We divide economic activity into a number of distinct but interdependent outputs that are non-substitutable in the short-term. The dynamic aspects assume that supply follows demand, but are constrained in the short-term by physical infrastructure. At the same time, capital formation grows the physical infrastructure. Our model regenerates historical data dynamically as a basis for projecting forward scenarios to discuss pathways to a lower carbon future.
\end{abstract}

Keywords: Employment; Energy modelling; Feedback control; Fixed capital formation; GDP; Intermediate consumption. 
Final version appeared as: SH. Roberts, CJ. Axon, BD. Foran, NH. Goddard, \& BS. Warr (2016). A Robust Data-driven Macro-socioeconomic-energy Model. Trans IChemE Part E: Sustainable Production and Consumption, in press, DOI: 10.1016/j.spc.2016.01.003.

\section{Software availability}

Name of software

Contact

Programming environment

Availability

Download URL

Year first available

Hardware required

Software required

Program size
7see-GB

Dr. Simon H. Roberts (corresponding author)

Vensim

Freely available as a Vensim Reader version. The full model is also freely available from the corresponding author.

http://dx.doi.org/10.7488/ds/231

2015

$2.0 \mathrm{GHz}$ processor with $2 \mathrm{~Gb}$ memory

Windows (XP/Vista/7/8/8.1) or Macintosh OSX (10.4+)

$10 \mathrm{Mb}$

$\begin{array}{ll}\text { Abbreviations } & \\ \text { agri } & \text { agriculture industry } \\ \text { cnstr } & \text { construction industry } \\ d w l g & \text { dwellings } \\ \text { extr } & \text { extraction industry } \\ \text { manu } & \text { manufacturing industry } \\ \text { serv IR } & \text { service industry, including rental } \\ \text { serv } L R & \text { service industry, less rental } \\ \text { util } & \text { utility industry }\end{array}$

\section{Acronyms}

$\begin{array}{ll}\text { AFC } & \text { actual final consumption } \\ \text { BoP } & \text { balance of payments } \\ \text { CCGT } & \text { combined cycle gas turbine } \\ \text { CFC } & \text { consumption of fixed capital } \\ \text { CGE } & \text { Cemputable general equilibrium } \\ \text { CPC } & \text { fixed capital } \\ \text { FC } & \text { fixed capital formation } \\ \text { FCF } & \text { gross domestic product } \\ \text { GDP } & \text { gross fixed capital formation } \\ \text { GFCF } & \text { greenhouse gases } \\ \text { GHG } & \text { gross value added } \\ \text { GVA } & \text { intermediate consumption } \\ \text { IC } & \text { input-output } \\ \text { IO } & \text { input-output table } \\ \text { IOT } & \text { International Standard Industrial Classification } \\ \text { ISIC } & \text { non-profit institutions serving households } \\ \text { NPISH } & \text { production of a unique output from fixed capital } \\ \text { p } & \text { System of National Accounts } \\ \text { SNA } & \text { supply and use table } \\ \text { SUT } & \text { transport and trade margins } \\ \text { TTM } & \end{array}$


Final version appeared as: SH. Roberts, CJ. Axon, BD. Foran, NH. Goddard, \& BS. Warr (2016). A Robust Data-driven Macro-socioeconomic-energy Model. Trans IChemE Part E: Sustainable Production and Consumption, in press, DOI: 10.1016/j.spc.2016.01.003.

\section{Nomenclature}

\section{CFC}

e

$f$

$F C$

FC

FCF

$g$

j, $k$

M

n

$p$

p_sup

$q$

$r$

S

$t$

V

$V^{\prime}$

X flow of consumption of fixed capital of infrastructure vector representing the set of exogenous demand

final supply of industry output, at purchasers' prices

stock of fixed capital of infrastructure such as for an industry or of power stations

vector representing the set of $F C$

flow of fixed capital formation of infrastructure

final demand of industry output, at purchasers' prices

index numbers for type of infrastructure

imports

total number of types of infrastructure in a 7see model

production of a unique output, which from an industry is classified by type of industry, at basic prices

vector representing the set of output from the set of $F C$

supply of $p$ from an industry rearranged for classification by products, at basic prices

supply of industrial products in their form, directly following intermediate consumption, at basic prices

supply of $r$ after transfer from services of transport and trade margins, at basic prices

time

total modelled-demand for investment (GFCF)

damped total modelled-demand for investment (GFCF)

exports 
Final version appeared as: SH. Roberts, CJ. Axon, BD. Foran, NH. Goddard, \& BS. Warr (2016). A Robust Data-driven Macro-socioeconomic-energy Model. Trans IChemE Part E: Sustainable Production and Consumption, in press, DOI: 10.1016/j.spc.2016.01.003.

\section{Introduction}

In developed nations, economic activity leads to significant GHG emissions. Such activity is enabled and mediated by various infrastructures for energy, water, and power distribution, residential and commercial buildings, manufacturing, transport of people and goods, and information and communications networks. Such national-scale infrastructure (capital stock) tends to need large dedicated investment programmes which are short-lived compared to the asset lifetime, and can lead to lock-in of indirect and induced GHG emissions which are difficult to mitigate (Lecoq and Shalizi, 2014). The projected levels of investment required for a nation to transition to a low carbon economy are difficult to estimate. It is not clear what counts as 'low carbon' and governments are generous in estimating what sums might be raised and spent. There is renewal of transport infrastructure ready for a more electric future, electrification of heating, deployment of renewables, smart grid infrastructure, and refurbishment of the housing stock.

The UK Government aspires to spend over $£ 100$ bn between $2010-2020$ with $£ 375$ bn in the longerterm pipeline (HM Treasury, 2013). These demands compete for investment and resources within and across nations. The key question is how much investment can an economy afford? It is desirable to maintain an active broad-based economy and to ensure that levels of employment remain high, but there are trade-offs with resource availability.

Multi-sectoral economic modelling techniques are well established. Input-Output (IO) is the most widely used, partly because of the simplicity of its structure (Allan et al., 2012). It exploits intermediate consumption data from national accounts to derive direct and indirect changes in supply resulting from demand induced disturbance. Technical and production coefficients do not change since an IO model is typically for just one year, thus modelling the potential effects of policy changes requires other methods (McGregor et al., 2008). Furthermore, either spare production capacity is presumed, or that there are no constraints on capital because it is free to increase as producers are paid more. For the study of energy and resource use in economies, IO models have been used recently for GHG emissions due to consumption (Barrett et al., 2013; Duarte et al., 2013), supply chain life cycle assessment (Chang et al., 2014), and waste analysis (Lenzen and Reynolds, 2014).

The limitations of an IO model of supply simply following demand are addressed in computable general equilibrium (CGE) models. Both supply and demand are modelled systematically and simultaneously (Shoven and Whalley, 1992). Supply is disaggregated, such as into factors of production. Elasticities of substitution determine how far producers substitute between inputs in response to changes in relative prices. Calibration of static CGE models typically depends on data for a single year, and as such they represent structural transitions poorly, but this can be overcome by a dynamic CGE framework (Harrison et al., 2000; Lecca et al., 2013). A sequence of single-period equilibria can be linked through stock-flow relationships so that computed equilibria vary over time as the value for the model's stock variables adjust, thus endogenising growth (Dixon and Rimmer, 2002). But this brings the disadvantage that dynamic models are complex and more difficult to solve. Another limitation is that the elasticities of substitution cannot be directly derived from the same data, but depend on modellers' judgement or the need to use estimates from secondary sources. As with IO models, capital as a factor of production is presumed to be freely available, simply mediated through price.

The limitations in sourcing elasticities of substitution are avoided in macroeconometric models. These models make use of time-series data from which parameters are derived, often by linear regression. In dynamic stochastic general equilibrium (DSGE) models, agent maximisation of utility occurs within a stochastic environment, rather than a deterministic one (Marcellino and Rychalovska, 2014; Cervena and Schneider, 2014). Impacts of economic policy changes on aggregated variables in an economy can be explained by macroeconometric models. Unlike many CGE models, they often include detailed dynamic characteristics of the economy such as expectations, growth, capital accumulation, and resource depletion (Golosov et al., 2014). Furthermore, they are able to include market disequilibrium and monetary variables in a more sophisticated way. Macroeconometric modelling, like CGE modelling, is also constrained by adequacy and availability of data. Macroeconometric models have particular concerns with the time consistency of the data being used and the ability to model structural shifts over time (Allan et al., 2012). A set of frameworks - often hybridising economic modelling methodologies - are being used for analysing the economic impacts of energy policy-making that incorporate representations of the economy, the energy 
Final version appeared as: SH. Roberts, CJ. Axon, BD. Foran, NH. Goddard, \& BS. Warr (2016). A Robust Data-driven Macro-socioeconomic-energy Model. Trans IChemE Part E: Sustainable Production and Consumption, in press, DOI: 10.1016/j.spc.2016.01.003.

system and the environment in such a way that impacts in one should affect one or more of the others. With regard to energy, they depend on the volume measures of expenditure corresponding to consumption in physical units and thus are heavily dependent on price being an accurate representation. A prominent example being the demand-driven UK MDM-E3 (IO-based) model (Cambridge Econometrics, 2013). Examples of multinational models (with regional or global coverage) are the IO-based FIDELIO (Kratena et al., 2013), E3ME (Cambridge Econometrics, 2014), GINFORS (Lutz et al., 2010), and PANTA RHEI (Meyer, 2005; Bockermann et al., 2005); the CGE-based WorldScan (Lejour et al., 2006) and GEM-E3 (Capros et al., 2013); and the econometric-based NEMESIS (Zagamé et al., 2010).

Models using system dynamics form a distinct paradigm with different applications (Forrester, 2007; Richardson, 2011). System dynamics is well-suited, where there are concepts of stocks, to model institutionalism, decision modelling, natural resource and energy use, policy analysis, and other systems in which behaviour of agents can be introduced and examined to see the effects of proposed causal mechanisms. Interesting examples exploiting system dynamics for economics-energy studies are a national model for the US (Forrester et al., 1976; Forrester, 2013), sustainable development (Schembri, 1999), low or no growth scenarios (Victor and Rosenbluth, 2007), monetary policy analysis (John, 2012), and trade cycles (Harvey, 2013).

Our approach, which we refer to as '7see', has more in common with the biophysical economics and resource accounting (stocks and flows) approach (Dale et al., 2012a; Foran, 2011; Slesser and King, 1988) which models the relationships between embodied energy, physical materiality, and infrastructure. One disadvantage of these models is the lack of availability of appropriate datasets. However, such models have been applied to several nations and blocs: the UK (Slesser et al., 1994a,b; Crane, 1996), the Netherlands (Noorman, 1995; Battjes, 1999), Australia (Foran and Crane, 1998), New Zealand (Ryan, 1995) and the EU (Slesser et al., 1998; Spangenberg et al., 1998; Bockermann et al., 2005). The original (UK) ECCO model was inspired by the limits-to-growth approach of Meadows et al. (1972) and Roberts (1978). A recent model in a similar vein is GEMBA (Dale et al., 2012b). Compared to the UK ECCO model in developing our model, we have historical time series to calibrate relationships between key variables, used the financial measure of fixed capital (FC), extracted from the raw econometric data rather than attempting to convert these data to embodied energy, and aligned variables to categories present in standard national accounts to make the framework and model internationally compatible. However, we have in common with the family of national ECCO models the centrality of FC (though not its interpretation as embodied energy), production coefficients for energy requirements which do not depend on a price mechanism, and feedback control using shortfall in an industry output loop which brings about growth in the industrial base as part of meeting other needs. Chu et al. $(2011,2013)$ have shown that systems control theory, and in particular feedback, can be applied as model predictive control to a 7 see-type model.

What we note as missing from all these techniques is the incorporation of demands upon an economy to fulfil capital, more specifically fixed capital formation (FCF). We contend that FCF can be taken as an explicit flow rather than left to pricing signals with producers and the 'cost of capital'.

Although all models use exogenous parameters to varying extents, where possible a new model should be equilibrium-seeking method (for supply to match demand) at each point in time to endogenise other parameters. In addition, it should use time-series data for as many parameters as possible, and be calibrated and tested against a period of historical data. While appreciating the value that comes from using time-series data, it must be kept tractable and avoid becoming too complex.

\subsection{The 7see framework1}

The 7 see model is derived from a consistent and robust framework for methodically curating disparate types of data sources. The 7see framework (Roberts et al 2015) harmonises multiple national accounting procedures for economic, social, and energy-use elements in a modular fashion, and each data stream retains

\footnotetext{
${ }^{1}$ The name 7 see is derived from aggregating economies into six industries plus dwellings, and modelling using socioeconomic and energy data.
} 
Final version appeared as: SH. Roberts, CJ. Axon, BD. Foran, NH. Goddard, \& BS. Warr (2016). A Robust Data-driven Macro-socioeconomic-energy Model. Trans IChemE Part E: Sustainable Production and Consumption, in press, DOI: 10.1016/j.spc.2016.01.003.

its unique measurement unit and accounting requirements. The economic elements align within the constraints of the internationally accepted System of National Accounts (United Nations et al., 2009). The framework is neither an exclusively economic, physical, nor social model. This paper concerns converting the 7 see data framework into a computational model that regenerates historical data so as to defensibly run trends into the future. The 7see framework exploits time-series ratios, which we refer to as coefficients, between different measurement units to give key functional relationships that vary gradually over time. The framework is agnostic to the way in which a nation organises its economy although we assume a mechanism for reasonably efficient allocation of capital exists.

\subsection{Organisation of the paper}

The 7see data framework and model evolved whilst developing the UK case study. In this paper we present a generalised line of reasoning to show how it applies to other nations. We build up the model piecewise to show its construction.

Section 2 introduces concepts that define one module of a single type of infrastructure: one type of fixed capital (a stock) and its supply of a distinct output, relationships between the stock and the flows of fixed capital formation (FCF) and consumption of fixed capital (CFC), need for inputs, comparison of model-generated supply to exogenous and other demand, one equilibrium-seeking feedback loop, and calibration to historical time-series data.

Section 3 builds up a complete dynamic model for a whole economy from single modules. This focuses on distinct production of the three major industries, investment, and behaviour of feedback loops.

Section 4 shows how to configure a model for a specific country, including tuning of positivefeedback loops. We consider how to judge the quality of a model and propose appropriate tests for a 7 seetype model.

\section{Modelling paradigm and methodology}

The '7see approach' expresses constraints between components of the macroeconomy (for example, capital stocks and gross fixed capital formation, GFCF). By operationalising a 7 see data framework, the model does not rely on optimisation. In the SNA (2008) the term 'stock' applies only to the assets resulting from GFCF, following their definition as lasting longer than one year, and inventories (the small proportion of goods carried over from one year to the next). Thus any flow being used up in one year is a non-stock variable for the purposes of our system boundary. An example of a non-stock variable is the supply of services produced by the FC of the service industry.

As we must be able to model stock and non-stock variables and their flows, a pure system dynamics approach is not suitable. Hence, we use system dynamics for the interaction of FCF with FC, but implement directly a control theory method for the equilibrium-seeking supply and demand balance. We treat the economy as demand-led with the difference between total demand and model-derived supply, from FC, giving rise to a shortfall that controls FCF.

The system dynamics paradigm allows natural feedbacks to be modelled with constraints from interactions between variables, and then uses iterative time-stepped simulation to evolve the model of the system forward in time. Useful introductions to system dynamics and relevant techniques are to be found in Radzicki (1988), Sterman (2000), Coyle (2001), and Harvey (2013). The fundamental components of a system dynamics model are: 1) stocks of entities in the system; 2) flows that affect the level of stocks and 3) equations linking the level of stocks to the flow rates. In addition, we have flows not from (or to) stocks that we distinguish by referring to as auxiliaries. We use iterative time-stepped simulation to evolve the model of the system forward in time with equations representing influences - in representing any complex system some of these influences will form feedback loops (Hayward and Boswell, 2014; Mollerup et al., 2015). Thus we are dealing with a dynamical system model in which the interplay of positive and negative feedback mechanisms will drive system behaviour (Kelly et al., 2013). The feedback control implemented for the nonstock variables is discussed in sections 3.5 and 3.6 and Appendix C. In section 4.1 and Appendix E it is applied to the case study. We note that success in regenerating historical data through feedback loops cannot be presumed. Its successful outcome is a minimum step in being able to go on to using the model for future scenarios. 
Final version appeared as: SH. Roberts, CJ. Axon, BD. Foran, NH. Goddard, \& BS. Warr (2016). A Robust Data-driven Macro-socioeconomic-energy Model. Trans IChemE Part E: Sustainable Production and Consumption, in press, DOI: 10.1016/j.spc.2016.01.003.

Our model is implemented in Vensim 5.8b, running on a Windows platform. A complete model run takes under a second on a $2.4 \mathrm{GHz}$ Intel-based PC. External data management is conducted using Microsoft Excel.

\subsection{Assumptions and basic principles}

In modelling the framework, we make the following assumptions.

- Supply of distinct net outputs from production (p) are non-substitutable in the short-term. We define short-term non-substitutability as a shift from one type of supply to another that needs investment in fixed capital (FC). For example, a shift from gas to electricity for domestic heating will mean changing the equipment in many homes which will take years if not decades.

- Supply $p$ of each distinct output is determined by FC. FC is the capital stock of a type of infrastructure and includes machinery, transport equipment, and buildings or other structures that are used repeatedly or continuously in production over several accounting periods (more than one year).

- Supply $\mathrm{p}$ is proportional to the stock of FC; constant returns to scale (linear scaling).

- Inputs to FC are proportional to the single output $\mathrm{p}$ it produces (linear scaling).

- Output coefficients, relating infrastructure output $\mathrm{p}$ to $\mathrm{FC}$, and production coefficients, relating inputs to output $\mathrm{p}$, are independent.

- Supply of most of the distinct outputs seeks to follow demand but is constrained by FC (its sole producer) so is resolved by feedback.

- The volume of each distinct output $\mathrm{p}$ is fully accounted for such that it seeks to balance with all destinations of its demand.

- We treat exogenously (not determined by the model) final demand of actual final consumption and exports, rate of building for dwellings, rate of new road vehicles and changes in population.

- The stock of FC requires the in-flow of FCF for maintenance and growth.

- The total availability of flow FCF is in limited supply.

A key principle of a 7see-type model is that an economy is made up of types of infrastructure (e.g. power stations and factories) each of which consume and transform one or more inputs (e.g. fuel energy and products from other industries) to produce a unique output (e.g. electricity and goods) that itself seeks to meet demand. We represent each type of infrastructure $\mathrm{j}$ in Fig. 1 in which the unique output $p_{j}$ needing various inputs is produced by a stock of $F C_{j}$ that itself needs an in-flow of $F C F_{j} . \quad F C_{j}$ also decreases as a result of physical deterioration or normal obsolescence, referred to as consumption of fixed capital (CFC). In Fig. 1(a) we show these basic concepts by introducing the representation used in this paper of vertical arrows for flows that alter stocks and horizontal arrows for auxiliary flows usually without an attached stock that we hereafter refer to variously as production, products, output, supply, demand and input. We note that the output $p_{j}$ does not necessarily end in a stock. Only where such outputs become assets that last longer than one year do they become the source of an FCF flow. Most variables of interest, such as goods and services, are assumed to be consumed in the same time-period in which they are produced - there is no modelling of inventory. The identification of FC in the economy with the stock concept is a reflection of the categorical difference in the 7see model between FC and other types of economic stocks such as inventories. 
Final version appeared as: SH. Roberts, CJ. Axon, BD. Foran, NH. Goddard, \& BS. Warr (2016). A Robust Data-driven Macro-socioeconomic-energy Model. Trans IChemE Part E: Sustainable Production and Consumption, in press, DOI: 10.1016/j.spc.2016.01.003.

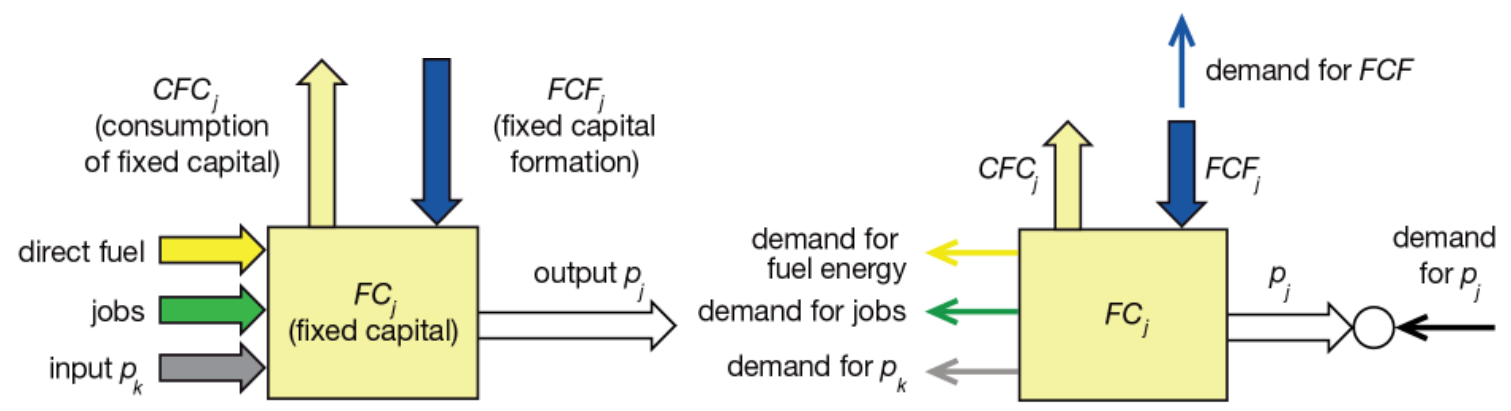

(a)

(b)

Fig. 1. The basic elements of a 7see-type model consist of a type of infrastructure of size $F C_{j}$ which is the total producer of a distinct output $p_{j}$ using various inputs including other products $p_{k}(k \neq j)$. Part (a) shows a simplified view of an economy in which infrastructure transforms several inputs into a single output. In (b) we present our modelling approach of distinguishing all of the demands necessary to produce output $p_{j}$ as well as the demand for $p_{j}$ itself.

A 7see-type model maintains separate accounts of all the different outputs, whether types of energy, economic production or other outputs. With manufacturing, as other industries, we quantify its output by the general measure of gross value added (GVA). The sum of GVA across an economy is its gross domestic product (GDP). The accounts of energy are in energy units $(\mathrm{PJ} / \mathrm{y}$ or $\mathrm{TWh} / \mathrm{y})$ rather than in monetary units of economic volume flows (Roberts et al., 2015).

We categorise industries and their production according to the International Standard Industrial Classification (United Nations, 2008a) or ISIC and then categorise products according to the Central Product Classification (United Nations, 2008b) or CPC (Table 1). Products according to this pair of classifications do not have an exact one-to-one correspondence (Appendix A). We later designate production according to products by $q_{j}$. For supply of energy, we separately identify their infrastructure within appropriate industries: biomass within agriculture, fossil fuels within extraction, electricity within utilities, and petroleum products within manufacturing. Distinct outputs whose sources are not wholly determined by infrastructure include imports, fuels and the economically active population (available to fulfil jobs).

Table 1. The six industries (by ISIC) within a 7see-type model and their related products (by CPC) together with dwellings and rental.

\begin{tabular}{|c|c|c|c|c|}
\hline Industry & Description & ISIC & Product & CPC \\
\hline 1 agri & $\begin{array}{l}\text { agriculture, forestry and } \\
\text { fishing }\end{array}$ & section $\mathrm{A}$ & $\begin{array}{l}\text { agriculture, forestry and } \\
\text { fishing products }\end{array}$ & section 0 \\
\hline 2 extr & mining and quarrying & section B & ores and minerals & $\begin{array}{l}\text { divisions } 11- \\
16\end{array}$ \\
\hline 3 util & $\begin{array}{l}\text { supply of electricity, gas, } \\
\text { water and water remediation }\end{array}$ & sections $\mathrm{D}$ and $\mathrm{E}$ & electricity, gas and water & $\begin{array}{l}\text { divisions } 17- \\
18\end{array}$ \\
\hline 4 тапи & manufacturing & section $\mathrm{C}$ & goods from manufacturing & sections $2-4$ \\
\hline 5 cnstr & construction & section $\mathrm{F}$ & construction services & section 5 \\
\hline $6 \operatorname{serv} L R$ & service industry & sections $\mathrm{G}$ to $\mathrm{U}$ & services (less rental) & $\begin{array}{l}\text { sections } 6-9 \\
\text { less class } 7211\end{array}$ \\
\hline $7 \quad d w l g$ & (dwellings) & & $\begin{array}{l}\text { rental from dwellings } \\
\text { (actual and imputed) }\end{array}$ & class 7211 \\
\hline
\end{tabular}

In Fig. 1(b) we introduce the modelling approach in this paper of demand, both for the unique output, $p_{j}$, as well as its need for various inputs and $F C F_{j}$. 
Final version appeared as: SH. Roberts, CJ. Axon, BD. Foran, NH. Goddard, \& BS. Warr (2016). A Robust Data-driven Macro-socioeconomic-energy Model. Trans IChemE Part E: Sustainable Production and Consumption, in press, DOI: 10.1016/j.spc.2016.01.003.

\subsection{The single infrastructure module and its unique output}

We consider the details of one unique output as a 'module- $\mathrm{FC}_{\mathrm{j}}$ ' corresponding to infrastructure $F C_{j}$ within our model of the economy and the supply and demand of output $p_{j}$. In Fig. 2(a), characters $\alpha$ to $\eta$ denote historical time series for one module- $\mathrm{FC}_{\mathrm{j}}$.

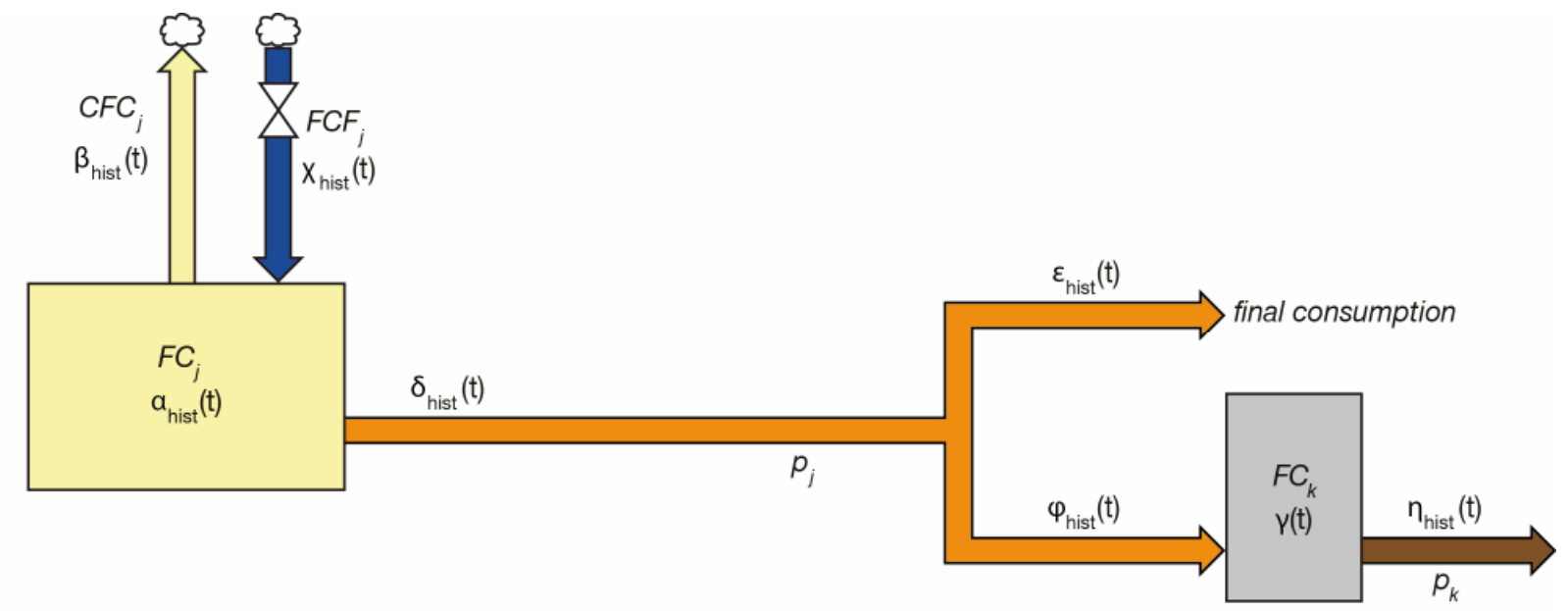

(a)

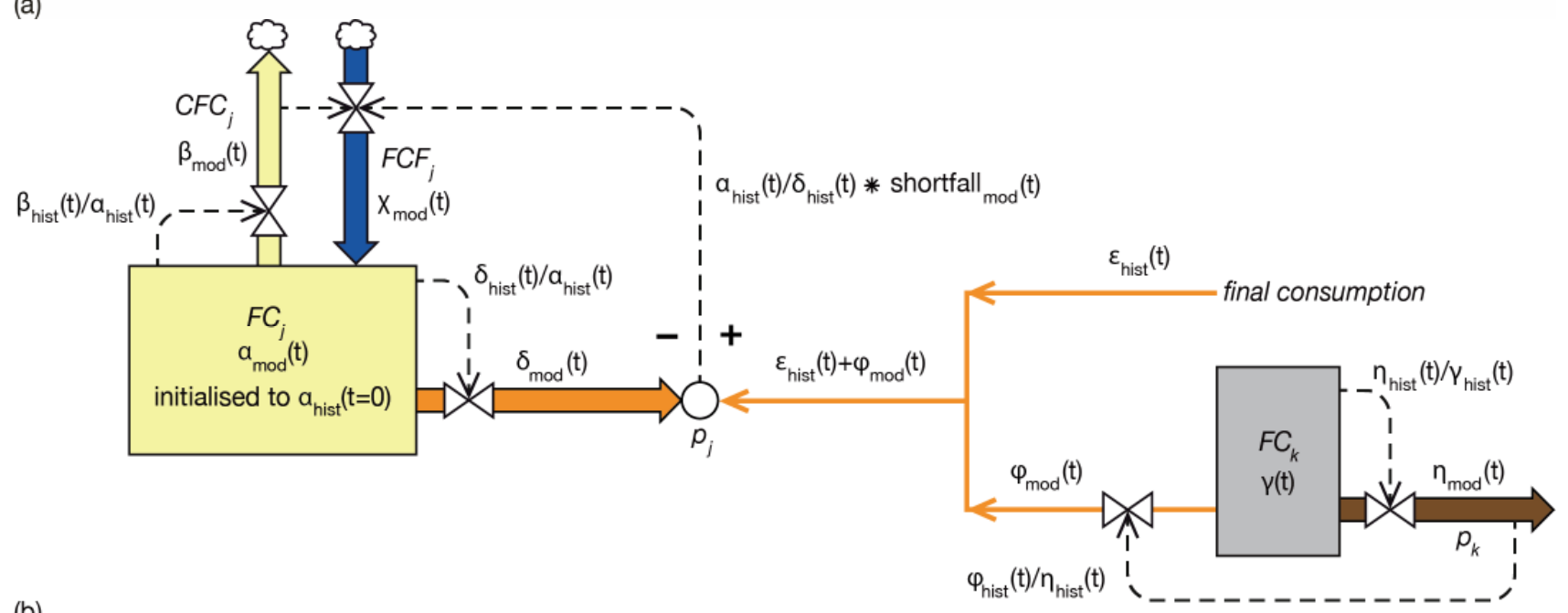

Fig. 2. Details of module-FC $\mathrm{j}_{\mathrm{j}}$ for a type of infrastructure and its own distinct output $p_{j}$ : (a) historical time-series data; (b) operationalised in the model with the circle marking the point where the model-generated supply needs to be reconciled with total demand.

The infrastructure's fixed capital $F C_{j}$ is $\alpha$, which decreases by $\beta$ representing CFC and increases by $\chi$ representing FCF. The FC $\alpha$ is a stock whilst $\beta$ and $\chi$ are flows that change this level with time $(\mathrm{d} F C / \mathrm{d} t)$. The unique production of infrastructure $F C_{j}$ is the supply $p_{j}$ with this output represented by $\delta$. For the purposes of illustration of the generic case, the supply of output $p_{j}$ has just two destinations. Demand $\varepsilon$ is final consumption, which could be by households. In contrast, demand $\varphi$ is input to infrastructure $F C_{k}(\mathrm{k} \neq \mathrm{j})$. Though we label this second infrastructure as having FC size $\gamma$, of more relevance here is its output $p_{k}$ denoted by $\eta$. Fig. 2(a) covers all the data available for a generic module-FC $\mathrm{F}_{\mathrm{j}}$ with which we now set out to construct a model.

Fig. 2(b) shows how these historical time-series data are converted into module- $\mathrm{FC}_{\mathrm{j}}$ of the model. We introduce the subscript mod to distinguish endogenous modelled values from historical exogenous data. We identify all demands as being in the reverse direction (right to left) and distinguish the point (by a circle) at which model-generated supply needs to meet total demand (section 2.3). In most cases the flows and outputs are regulated endogenously (within the model), and we show this control by bowtie symbols. We 
Final version appeared as: SH. Roberts, CJ. Axon, BD. Foran, NH. Goddard, \& BS. Warr (2016). A Robust Data-driven Macro-socioeconomic-energy Model. Trans IChemE Part E: Sustainable Production and Consumption, in press, DOI: 10.1016/j.spc.2016.01.003.

refer to $\varepsilon$ as an exogenous demand variable which adheres to historical data. Flow $\beta$, outputs $\delta$ and $\eta$, and demand $\varphi$ are determined by calculation. We take these relationships as linear using time-dependent coefficients and refer to them as exogenous data variables since calibrated from the historical data; pairs of historical time series reduce to time-series ratios. For example, $\beta_{\text {mod }}(t)$ is derived from $\alpha_{\text {mod }}(t)$ by multiplying by the coefficient $\beta_{\text {hist }}(\mathrm{t}) / \alpha_{\text {hist }}(\mathrm{t})$, which we refer to as a $C F C$ coefficient. The CFC coefficient is related to the lifetime of the related fixed capital; a value of 0.1 per year would correspond to a 10 -year lifetime. The coefficient for $\delta$ could be called economic performance of the asset or the return on (fixed) capital, which we now refer to as an output coefficient. The coefficient for demand $\varphi$ is the amount of input required to produce one unit of output; its input intensity, hereafter referred to as a production coefficient. To maintain the stock of $\alpha$, the flow $\beta$ contributes to the control of flow $\chi$. In the case where $\chi=\beta$, then the stock of $\alpha$ remains constant.

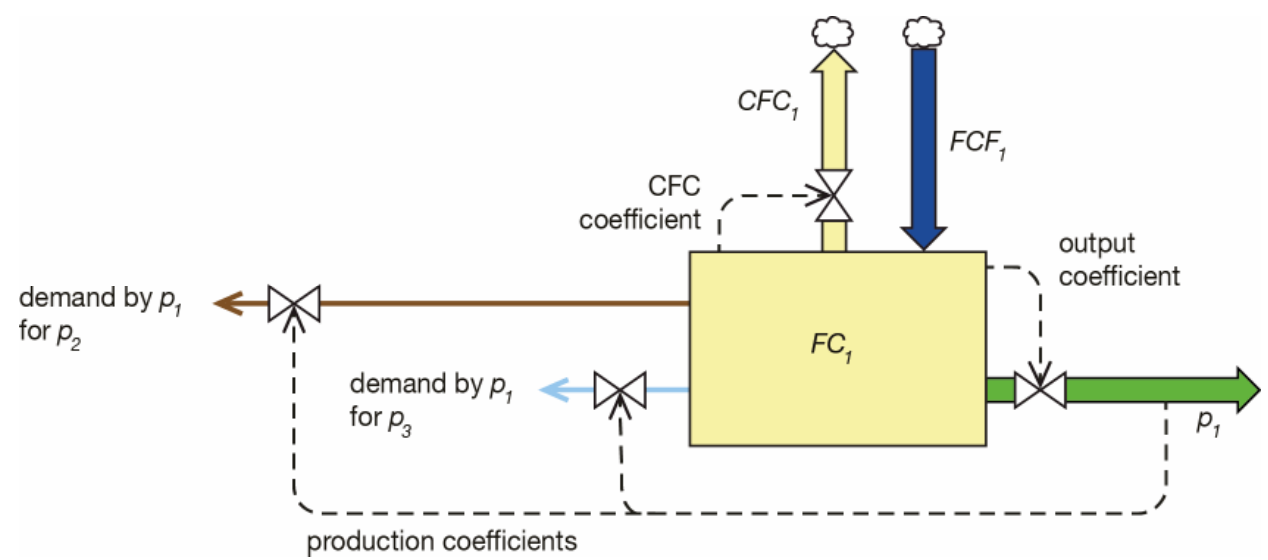

Fig. 3. Summary of the coefficients of CFC, output and production for infrastructure $F C_{l}$ and supply $p_{l}$.

We summarise the coefficients introduced in Fig. 3 and detail their mathematical form. For $C F C_{j}$,

$$
C F C_{j}=C F C_{-} \operatorname{coef}_{j} \cdot F C_{j} .
$$

For output $p_{j}$ supplied from infrastructure $F C_{j}$,

$$
p_{j-} \sup =\text { output_coef } f_{j} \cdot F C_{j} .
$$

For each $p_{k j}(\mathrm{k} \neq \mathrm{j})$ that is demand for $p_{k}$ from other infrastructure by $p_{j}$,

$$
p_{k j-} d m d=\text { prod_coef } f_{k j} \cdot p_{j-} \sup .
$$

As an example, consider a power station for $F C_{1}$ in Fig. 3. The stock $F C_{1}$ would be generation capacity in GW and $p_{l}$ would be output in TWh/y. The output coefficient would be load factor, the proportion of time when in use (capacity factor, duty factor or duty cycle). Output $p_{1}$ requires fuel input $p_{2}$. The production coefficient would be power station efficiency (transforming the energy content of the fuel into electricity). We suggest these concepts of load factor (output coefficient) and energy conversion efficiency (production coefficient) are helpful ways to consider other relationships across the economy. Production coefficients cover inputs of fuel for combustion, electricity, labour and products supplied from other industries (section 3) with their derivation in Appendix A.

Where energy is an input, we use production coefficients with respect to energy units, not the price of energy. For example, the units of the production coefficient could be PJ of natural gas per £m[1990] of goods produced by manufacturing. The actual economic volume flows for energy, corresponding to the 
Final version appeared as: SH. Roberts, CJ. Axon, BD. Foran, NH. Goddard, \& BS. Warr (2016). A Robust Data-driven Macro-socioeconomic-energy Model. Trans IChemE Part E: Sustainable Production and Consumption, in press, DOI: 10.1016/j.spc.2016.01.003.

payments made for energy, make up a very small proportion of GDP. Nevertheless we track them in a 7seetype model, along with rental for dwellings, to properly compute the total GDP.

\subsection{Supply-demand reconciliation through feedback}

The supply of each distinct output is demand-lead, but constrained by the stock of FC in the short-term. In Fig. 2(b), demand for the output of $F C_{j}$ is the sum of $\varepsilon$ and $\varphi$. This sum is compared to modelled-supply, $\delta$, with the difference called the shortfall derived at the circle (Mollerup et al., 2015). By applying feedback control (Åström and Murray, 2008), shortfall determines FCF. This can be thought of as a company managing production to meet demand according to the order-book ahead and keeping over- (or under-) supply to a minimum. A well-functioning economy has many feedback paths, some mediated through prices in markets. While the shortfall is a modelling device, its operation is one way of saying that the markets and other economic mechanisms are presumed to be working efficiently in directing the minimum investment going to the stock of FC necessary to meet final demand anticipated in the next time step.

In the generic example of Fig. 2(b), the shortfall of output $\delta$ is used to adjust the flow of $\chi$ which adjusts the stock of $\alpha$ and this in turn adjusts supply $\delta$ to reduce the shortfall. Although $\chi$ could be fully controlled by feedback alone, control is better if $\chi$ is set equal to $\beta$ with the shortfall providing an offset. If there is oversupply such that the shortfall is negative, then $\chi$ simply becomes smaller without going negative (unless the shortfall is very large or CFC is small).

We now complete our introduction of the mathematical description by linking together FC of all infrastructure. As is standard in feedback control, shortfall is simply the difference between a set-point (the total demand for $p_{j}$ ) and a measured value (the supply of $p_{j}$ )

$$
\text { shortfall }=p_{j-} \text { tot_dmd }-p_{j-} \sup .
$$

The total demand for $p_{j}$ is made up of the exogenous demand and demand $p_{j k}$ by other infrastructure $k$ according to Eq. (3)

$$
p_{j-} t o t_{-} d m d=p_{j-} d m d_{-} \text {exog }+\sum_{k, k \neq j} \operatorname{prod}{ }_{-} \operatorname{coef}_{j k} \cdot p_{k-} \sup .
$$

In feedback control, the transfer function of a conventional PI (proportional-integral) controller is represented for the control signal $u$ by the control error $e$ (Åström and Murray, 2008) by

$$
u(t)=k_{p} e(t)+k_{i} \int_{0}^{t} e(\tau) d t,
$$

where $k_{p}$ is proportional gain, $k_{i}$ is integral gain, $t$ is time and $\tau$ is the variable of integration from time 0 to $t$. Initially we use only the proportional term and the offset CFC described above, thus

$$
F C F_{j}=C_{F} C_{j}+\text { prop }_{-} \text {gain }_{j} \cdot \text { shortfall }_{j} .
$$

The rate of change of each stock $F C$ is determined only by its flows $F C F$ and $C F C$, thus

$$
\frac{d F C_{j}}{d t}=F C F_{j}-C F C_{j} .
$$

We can now build up the full model from single module units. We introduce the vector $\mathbf{F C}=\left(F C_{l}\right.$, $\left.F C_{2}, \ldots F C_{n}\right)$ to represent the set of FC, the vector $\mathbf{p}_{-}$sup $=\left(p_{1 \_}\right.$sup, $p_{2 \_}$sup $\ldots p_{n \_}$sup $)$to represent the set of output from $\mathrm{FC}$, and the vector $\mathbf{e}=\left(e_{1}, e_{2}, \ldots e_{n}\right)$ to represent the set of exogenous demand. Considering the 
Final version appeared as: SH. Roberts, CJ. Axon, BD. Foran, NH. Goddard, \& BS. Warr (2016). A Robust Data-driven Macro-socioeconomic-energy Model. Trans IChemE Part E: Sustainable Production and Consumption, in press, DOI: 10.1016/j.spc.2016.01.003.

right-hand side of Eq. (8), $C F C$ is a function of $F C$ from Eq. (1), and $F C F$ is a function of $\mathbf{p} \_s u p$ and $\mathbf{e}$ from Eq. (3), Eq. (4), Eq. (5), and Eq. (7). From Eq. (2), p_sup is a function of FC. Therefore

$$
\frac{d F C_{j}}{d t}=f_{j}(\mathbf{F C}, \mathbf{e})
$$

Thus we have a set of first-order ordinary differential equations which can be readily integrated numerically using Vensim. We detail a finite-time-step sequence in Appendix B.

The units of $F C F$ are monetary units per unit time of GFCF (investment), which is made up of the economic volumes of goods, construction services and other services. The units of $p$ are various including the economic volume flows of each unique product and electricity (TWh/y). An example of the units for the shortfall multiplier of proportional gain in the case of electricity generation would be economic volume of GFCF divided by TWh/y. This follows from the shortfall multiplier in Fig. 2(b) of $\alpha_{\text {hist }}(t) / \delta_{\text {hist }}(t)$. Later we introduce feedback paths that cross between unique outputs when we need to adjust the level of proportional gain to optimise dynamic behaviour. If there is a persistent offset of supply of unique output compared to demand, we can extend to two-term control by including the integral term in Eq. (6). The integral term is a way of including the history of the shortfall.

The method of the model is to initialise stocks $\left(F C_{1}, F C_{2}, \ldots\right)$ at $t=0$ and run forwards using only the time-dependent relationship coefficients (from historical exogenous data) and exogenous demand. Although historical data is quantised to annual steps, the model can be run with an arbitrary time-step size; we use 16 steps per year. We take the time response of the control feedback as occurring within one time step.

When we initialise stocks we also initialise the shortfall to zero, but we require the feedback component to settle quickly to the dynamic equilibrium condition when shortfall is non-zero. We speed up this settling period by adding to the shortfall at $t=0$ a fixed contribution as necessary for the resulting $F C F$ to match the historical value. We reduce this fixed contribution to zero with a decay factor of 1.3 years for a smooth transition to the model-generated shortfall.

\section{From a single module to a full system}

Following Roberts et al (2015) we consider the distinct products that make up a whole economy and combine their module- $\mathrm{FC}_{\mathrm{j}}(j=1 \ldots \mathrm{n})$ to create a national model. For transparency and critical evaluation we show how the model is built up stepwise.

\subsection{Industry interactions}

Our approach generally works with six industries and products (Table 1) together with dwellings. Under services we separate rental ('serv LR') since we assign it to dwellings. Separating rental from the output of the service industry means that service better reflects the product resulting from the fixed capital and inputs to the service industry. Examples of other products are detailed in Appendix D.

Intermediate consumption (IC) is the supply of products of one industry as inputs to another. The stages between different industries' value-added output up to the point of final supply are summarised in Fig. 4 for the three larger industries of manufacturing, construction and service industry (less rental), labelled four to six respectively.

In Fig. 4, stocks FC are represented as pairs of boxes whose facing sides are dotted (as if they are split apart). Production as GVA emerges from the left box with IC of other industries' GVA treated as a demand by the right box so represented by backward, demand arrows. White squares mark points where demand adds or subtracts from a flow. The actual sequence of production steps can be in any order and more complex. Fig. 4 extends the key principle of Fig. 1 in several ways:

- Supply categorised by industry $p$ is converted to categorisation by product $q$.

- Domestic production of products $q_{4}$ and $q_{6}$ are supplemented by their respective imports, $M_{4}$ and $M_{6}$, to create a total supply for the economy, where imports are handled as a demand (see Fig. C.1(c) and (d)). 
Final version appeared as: SH. Roberts, CJ. Axon, BD. Foran, NH. Goddard, \& BS. Warr (2016). A Robust Data-driven Macro-socioeconomic-energy Model. Trans IChemE Part E: Sustainable Production and Consumption, in press, DOI: 10.1016/j.spc.2016.01.003.

- The interaction of three distinct products, $q_{4}$ to $q_{6}$, is equivalent to a $3 \times 3$ matrix interaction, resulting in evolved products, $r_{4}$ to $r_{6}$ (not shown explicitly in Fig. 4 but detailed in Appendix A).

- After $r$ there is a further transfer of service industry product to manufacturing, explicitly for transport and trade, giving rise to $s$.

- Evolved products $s_{4}$ to $s_{6}$ form the products following intermediate consumption (IC) and transport and trade margins (TTM).

- Final products $f$ are at purchasers' prices through addition of tax (less any subsidies) on products.

For construction in Fig. 4, its imports are omitted because these are insignificant in the national accounts for many countries.

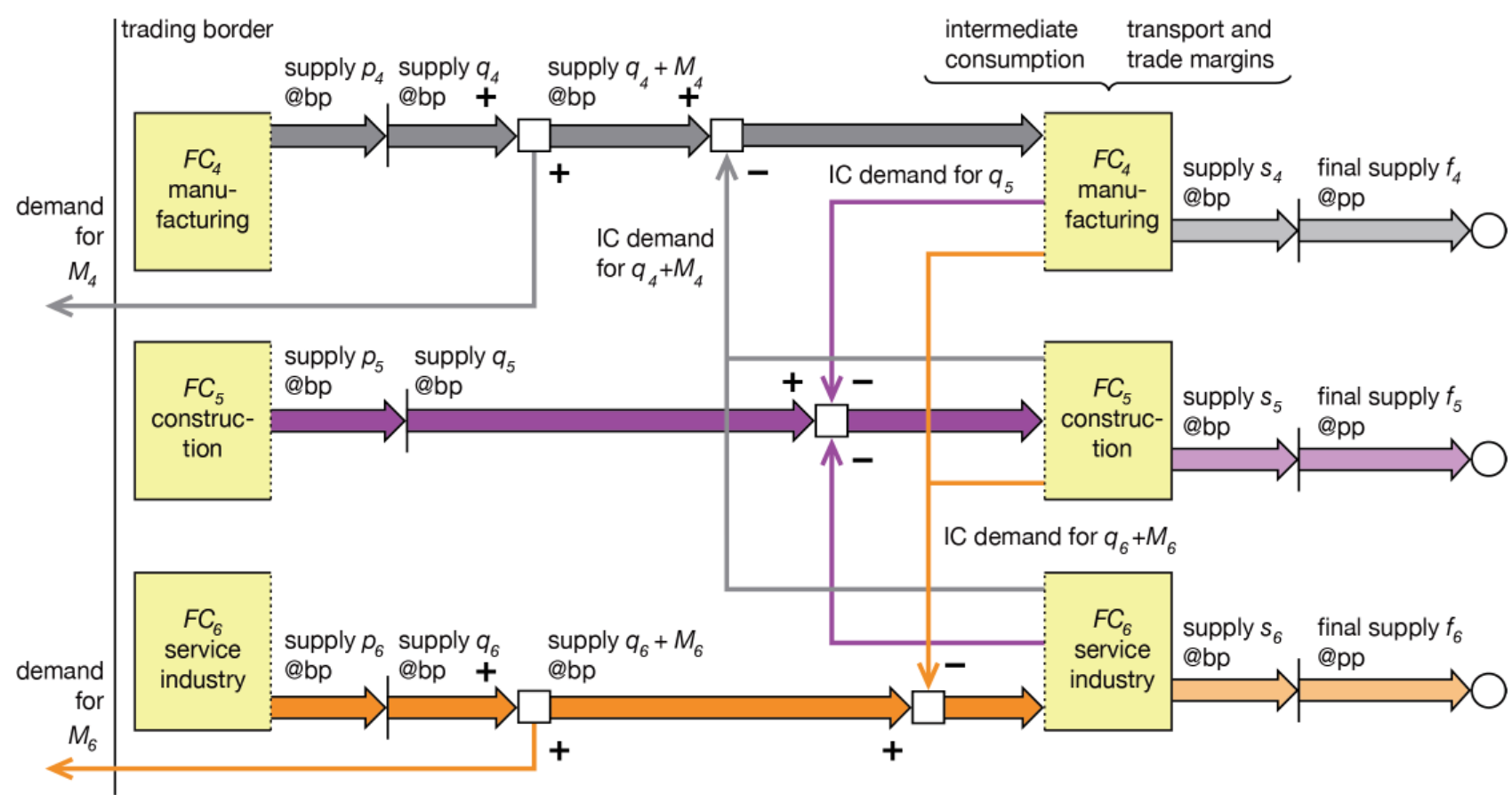

Fig. 4. Extension of the unique supply $p=4$ to 6 from manufacturing, construction and service industry respectively (all at basic prices) following IC to produce evolved products, $f=4$ to 6 , at purchasers' prices up to the circle where each supply will be reconciled with its total demand. IC involving $q$ of 1 to 3 is left off for clarity and because the size of their product volumes is small. (M: imports; @ bp: economic volume at basic prices; IC: intermediate consumption; @pp: economic volume at purchasers' prices after addition of net taxation on products.) Supplies $p, q, s$ and $f$ are detailed in Appendix A.3.

\subsection{Production coefficients}

In the case of industries whose products supply each other through IC, derivation of the timevarying production coefficients needs special attention. We track these data over the historical period.

Production coefficients for industry products are derived from Supply and Use Tables (SUT) which we review in Appendix A. The SNA (United Nations et al., 2009) introduces the matrix A of coefficients $\mathrm{a}_{\mathrm{ij}}$ : the amount of products i's (the rows) needed to produce one unit of industry j's products (the columns). However, this 'total output' of products at all stages does not equate to output $\eta$ (Fig. 2(b)) nor any of the concepts in Fig. 4.

We can explain total output as it appears in Supply and Use Tables through an example. Consider extracted coal used for electricity generation, as used by a dairy to milk cows whose milk becomes butter. This production chain proceeds through the industries in Table 1 of extr, util, agri and manu. Each transaction is IC and its full cost is included in SUT since that is how the data is gathered from the submissions of data by all establishments. Thus the cost of coal is included three times in this example. The 
Final version appeared as: SH. Roberts, CJ. Axon, BD. Foran, NH. Goddard, \& BS. Warr (2016). A Robust Data-driven Macro-socioeconomic-energy Model. Trans IChemE Part E: Sustainable Production and Consumption, in press, DOI: 10.1016/j.spc.2016.01.003.

more an economy consists of establishments trading which each other, the larger the total output of the economy, yet its GDP as the sum of GVA remains unchanged.

In Appendix A we show how the same source data of SUT can be rearranged for coefficients with GVA, corresponding to $p$ of each industry, as the denominator in many cases (Fig. A.3) - a set of production coefficients. GVA is the standard denominator for production coefficients (input intensities) of other inputs such as energy, water, and raw materials. Also in Appendix A we introduce other coefficients: conversion from categorisation by industry (of GVA) to categorisation by product, the level of imports with respect to domestic production, the level of transport and trade margins (a special case of services), and the level of tax on products. Through these coefficients we are able to exploit the annual publication of SUT to derive coefficients (from historical exogenous data) for all parts of Fig. 4. With reference to these coefficients, production as classified by products, $q$, is

$q_{j-} \sup =p q_{-} \operatorname{coef}_{j} \cdot p_{j-} \sup$

and we treat imports, $\mathrm{M}$, as linearly dependent on $q$ (section 3.5) as

$M_{j}=M_{-} \operatorname{coef}_{j} \cdot q_{j-} \sup$.

Noting the distinction we now make between $q$ and $p$, we put equation (2) in terms of demand by $p_{k}$ of other industries for $q_{j}$,

$q_{j k} I C_{-} d m d=p r o d_{-} c o e f_{j k} \cdot p_{k-} \sup$.

The outcome of IC (Fig. 4) is $r$ representing a product in its final form where

$r_{j}=q_{j}-\sup +M_{j}-\sum_{k, k \neq j} q_{j k-} I C_{-} d m d+\sum_{k, k \neq j} q_{k j-} I C \_d m d$.

In Fig. 4, the summation of $q_{j k \_} I C_{-} d m d$ is subtracted because it is the contribution of industry $\mathrm{j}$ by IC to other industries. The summation of $q_{k j-} I C_{-} d m d$ is added because it corresponds to IC consumption by industry $\mathrm{j}$. The transfer of services of transport and trade margins (TTM) is similar to Eq. (13), resulting in $s_{j}$ where $j$ does not include the service industry,

$s_{j}=r_{j}+T T M \operatorname{coef}_{j} \cdot r_{j}$,

and for the service industry

$s_{j}=r_{j}-\sum_{k, k \neq j}\left(r_{k}-s_{k}\right)$

Finally, taxes on products are applied to obtain the final supply

$$
f_{j-} \sup =\operatorname{tax}_{-} \operatorname{coef}_{j} \cdot s_{j} .
$$

\subsection{The iterative approach to determine industry output}

Another principle we need to extend to Fig. 4 is how to start with final supply of $f$ so as to determine supply of $p$ (equivalent in Fig. 2(b) to starting with the sum of $\varepsilon$ and $\varphi$ to determine the supply $\delta$ ). Conventionally the problem is approached by starting with final supply, which must be reconciled with demand, and working back up-stream along the production process to calculate the level of inputs necessary to meet the final 
Final version appeared as: SH. Roberts, CJ. Axon, BD. Foran, NH. Goddard, \& BS. Warr (2016). A Robust Data-driven Macro-socioeconomic-energy Model. Trans IChemE Part E: Sustainable Production and Consumption, in press, DOI: 10.1016/j.spc.2016.01.003.

demand - for instance the Leontief approach. A limitation of the widely used Leontief approach (Allan et al., 2012) is the requirement for a symmetrical matrix derived from national IO (input-output) data. These data are more comprehensive than SUT, but are compiled only for occasional years. Our approach considers it more important to have historical continuity (preferably annually) to elucidate the evolution of interactions captured by time-varying coefficients.

Our solution is the concept of a break of supply before demand, at the point of the circle, in order to introduce feedback control. We refer to the left side of the circle as final supply, noting that this is not a concept or term in SNA. When there is a non-zero shortfall between final supply and final demand, we seek to change GVA (through feedback to FCF and thus FC). The shortfall is calculated at each of the 16 sub-year steps. With repeated feedback steps, the shortfall converges to zero (Appendix D) - this mechanism clears the market within a few time steps. This is iterating industry production to meet final demand, rather than the one-step analytical approach of the Leontief inverse. We can rewrite Eq. (4) for this situation as

shortfall $g_{j}=g_{j-} d m d-f_{j-}$ sup,

and for these industries, Eq. (7) becomes

$F C F_{j}=C_{j} C_{j}$ prop $_{-}$gain $_{j} \cdot$ shortfall $_{-} g_{j} \cdot$

In Appendix $\mathrm{C}$ we detail other types of feedback in addition to the one represented by Eq. (17).

\subsection{Incorporating the investment flow}

Flow $F C F_{1}$ in Fig. 3 is investment whose source is not shown in that figure. Modules that contribute to investment as one of their final uses are part of a GFCF feedback loop (Fig. 5). We show later that this is positive feedback, which brings an additional level of system complexity. In Fig. 5 we complete the set of final uses by including actual final consumption (Roberts et al., 2015) and exports. Exports of construction are omitted here because these are insignificant in the national accounts for many countries.

In the formalism of national accounts (United Nations et al., 2009), the provision of FCF, as summed across the requirements of industries and dwellings, is one part of final demand, referred to as GFCF. (The FCF requirements of transport are included within the FC of industries. Private vehicle ownership is not regarded as FC in national accounts.) Each FCF includes some form of control (the bowtie icons), as we introduced in Fig. 2(b). These result in demand for FCF and this demand can be followed back upstream (progressing around clockwise) as it aggregates to GFCF and to its principal components of manufacturing, construction and services in their evolved forms of final demand, $g_{4}$ to $g_{6}$. Further progression clockwise reaches supply $p$ from the three larger industries. We show the details between supply $p$ and final supply $f$ in Fig. 4.

Considering Fig. 5, as demand for GFCF increases, final demand for manufacturing, construction and services will each increase by an amount which we approximate according to the proportions by which they make up GFCF from historical data including their time-varying behaviour. Control of this positive feedback is discussed in section 3.5. We can now compute GFCF following on from Eq. (7) for FCF,

$$
G F C F=\sum_{j} F C F_{j}
$$

We subdivide GFCF into its component supplies of final products by,

$$
G F C F_{j}=p G F C F{ }_{-} c o e f_{j} \cdot \mathrm{GFCF} .
$$

where the pGFCF coefficients are derived from historical data for each product and sum to unity for $j=4$ to 6 . We can complete Eq. (17) with 
Final version appeared as: SH. Roberts, CJ. Axon, BD. Foran, NH. Goddard, \& BS. Warr (2016). A Robust Data-driven Macro-socioeconomic-energy Model. Trans IChemE Part E: Sustainable Production and Consumption, in press, DOI: 10.1016/j.spc.2016.01.003.

$$
g_{j-} d m d=G F C F_{j}+\operatorname{exog} g_{-} d m d_{j}
$$

where exogenous demand for final products is made up of actual final consumption and exports (Fig. 5).

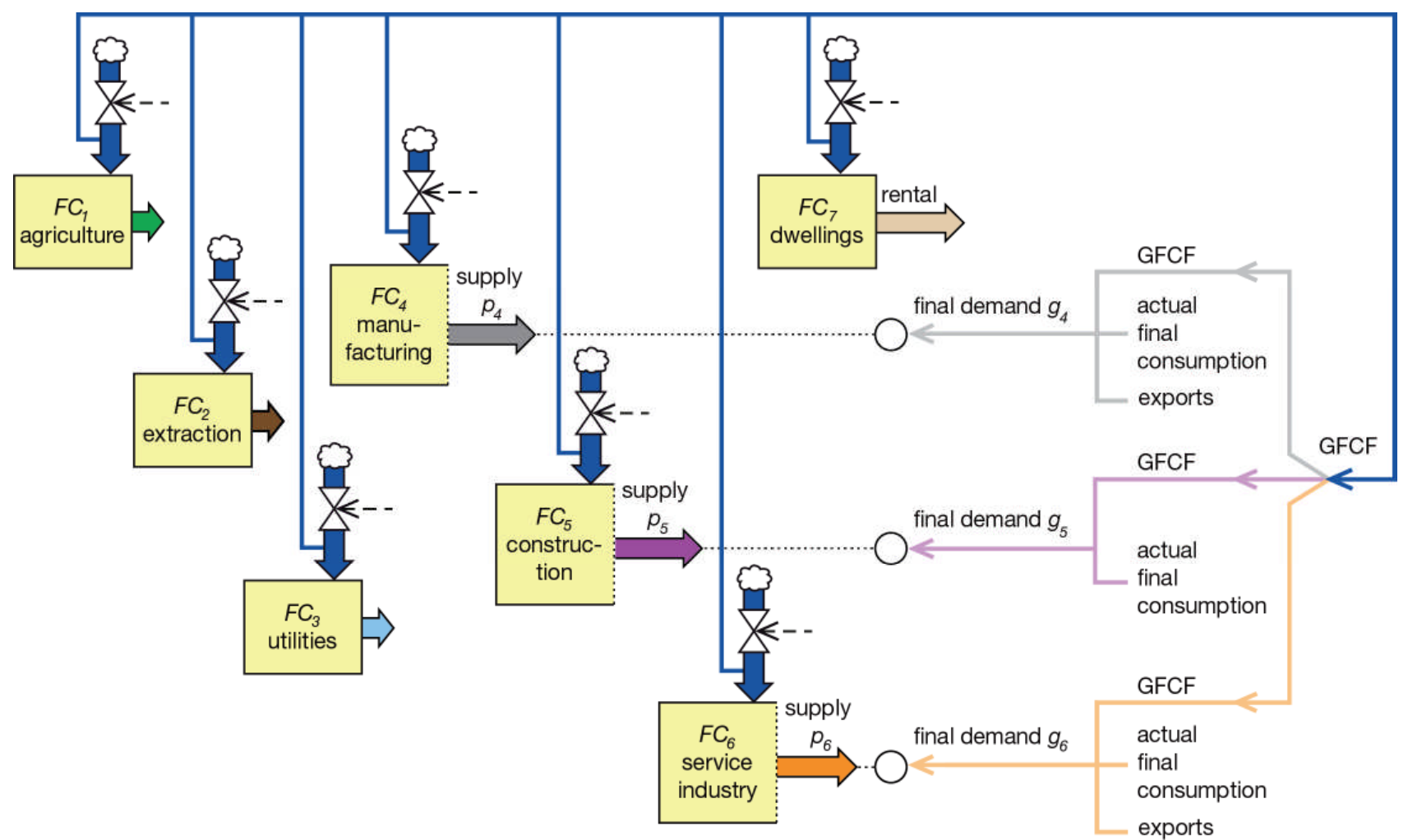

Fig. 5. Derivation of final demand $g_{4}$ to $g_{6}$ of the three larger industries from GFCF, the sum of demand $F C F_{1}$ to $F C F_{7}$. The small contributions from the industries, $F C_{1}$ to $F C_{3}$, are omitted for clarity. The dotted lines between supply $p_{4}$ to $p_{6}$ up to their circles are detailed in Fig. 4. The components of 'actual final consumption' are detailed in Fig. A.1(b), columns 18 to 20 .

\subsection{System-wide dynamic behaviour}

The system-wide interactions follow from:

- the supply $p$ of each of the three larger industries (manufacturing, construction and service industry) evolving into final supply $f$ (Fig. 4); and

- the requirements for change of each stock of FC serving as demand for GFCF, as supplied by the larger industries (Fig. 5).

Any loop in a system can be examined for its behaviour using so-called influence diagrams (Cellier, 1991). A plus or minus can be assigned to each link according to whether the change is in the same or opposite direction. Manufacturing, construction and the service industry each have two important loops (Fig. 6 ). An odd number of minuses in a loop means the feedback is negative (balancing) while a zero or even number means the feedback is positive (self-reinforcing). In Fig. 6 the direct effect on manufacturing output of the feedback is self-balancing (negative feedback). In contrast, manufacturing FCF gives rise to an increase for total investment. This is a self-reinforcing loop (positive feedback) so has the potential for runaway changes. 
Final version appeared as: SH. Roberts, CJ. Axon, BD. Foran, NH. Goddard, \& BS. Warr (2016). A Robust Data-driven Macro-socioeconomic-energy Model. Trans IChemE Part E: Sustainable Production and Consumption, in press, DOI: 10.1016/j.spc.2016.01.003.

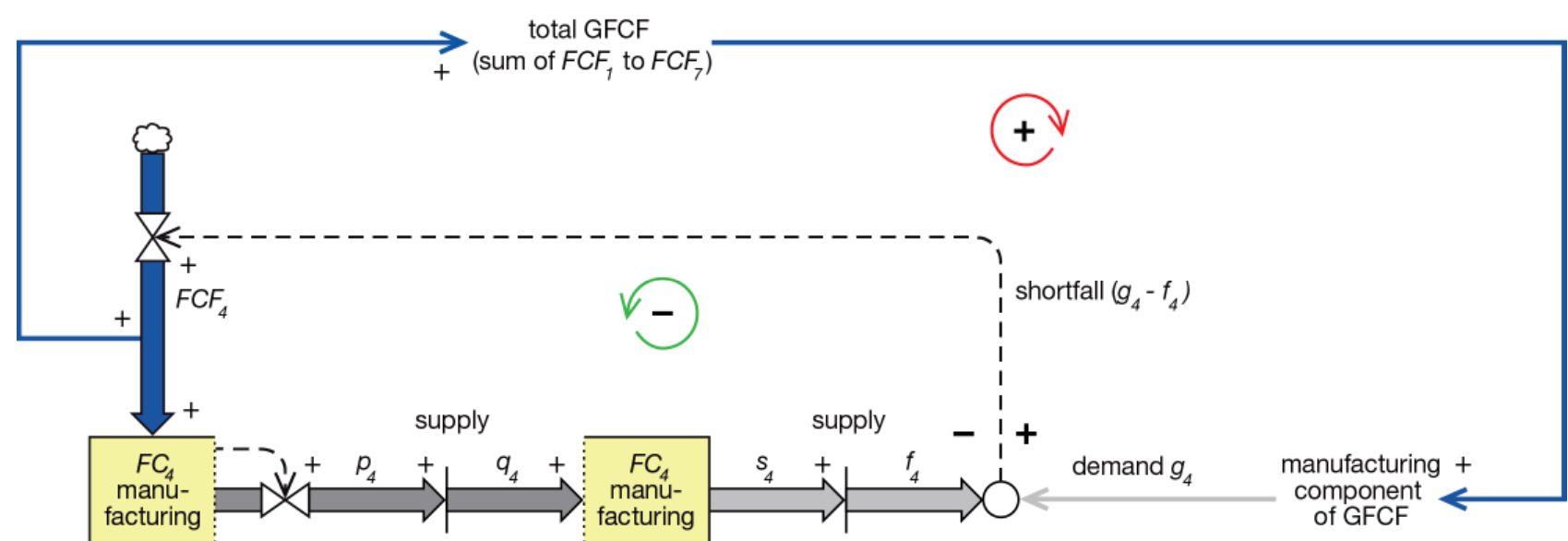

Fig. 6. An influence diagram of feedback loops using the manufacturing industry as an example: $F C_{4}$ determining supply $p_{4}$ is from Fig. 2(b); supply $q_{4}$ evolving into supply $s_{4}$ then $f_{4}$ is from Fig. 4 ; shortfall $\left(g_{4}-f_{4}\right)$ controlling $F C F_{4}$ of the manufacturing industry is from Fig. C.1(d); the increase in $F C F_{4}$ giving rise to increase of demand $g_{4}$ is from Fig. 5. These relationships show negative (green symbol) and positive (red symbol) types of feedback.

To illustrate these run-away changes, consider an increase in demand for goods from final consumption by households. This would signal the need for increased stock FC of manufacturing (factories) used for production upstream of goods. Since goods are a component of FCF required for increased FC of manufacturing, there is an additional increase in demand for goods. This additional demand would signal the need for increased FC of manufacturing, and so on.

Run-away changes can also work the other way giving rise to a rapid reduction. When there is falling demand for goods for household consumption, stock FC of manufacturing would decrease by flow FCF, its formation, becoming less than flow CFC, its consumption. The consequent reduction in GFCF would reduce demand for the goods contribution, signalling the need to reduce stock FC of manufacturing, and so on.

\subsection{Configuring feedback}

Most instances of negative feedback in a model do not need configuring. For example, in Fig. 2(b) the shortfall is in units of supply but impacts flow FCF which has different units (see also Fig. C.1(b)). This difference is resolved by setting proportional gain to the reciprocal of the output coefficient between FC and production to get into the same units. Reconciliation of supply with demand is virtually instant, only delayed by the modelling time step.

The case of Fig. 6 is not amenable to these approaches because the source of feedback at final supply $f$ is separated from supply $p$ by IC (Fig. 4) and involves the interaction of output from three different stocks of FC (see also Fig. C.1(d)). Feedback involving each final supply $f$ requires configuring separately for each country model.

The level of proportional gain (Eq. (7)) needs to be set for the negative feedback cases such that the system remains stable, yet responsive. We do repeated runs adjusting the proportion gain and examining the time response to annualised data, until we arrive at a match to historical data.

Positive feedback is only manifest in the investment loop and is of consequence to the three larger industries whose supplies make up investment (Fig. 5). Real economies have constraints which limit the positive feedback behaviour, such as a central bank's control of interest rates. A 7see-type model mimics the effect of these constraints to avoid oscillations in the model's behaviour. To reproduce the historical data without inducing oscillations, we use an exponentially-decaying weighted sum of previous target values to calculate each GFCF value. We set $V(t)$ to be the total modelled-demand for investment (GFCF) required at time $t$ and $V^{\prime}(t)$ to be the damped version having applied the exponentially-decaying weight sum.

$V^{\prime}(t)=V(t) \cdot(1-P)+V^{\prime}(t-1) \cdot P$

where $P$ representing the proportion of the previous value is 
Final version appeared as: SH. Roberts, CJ. Axon, BD. Foran, NH. Goddard, \& BS. Warr (2016). A Robust Data-driven Macro-socioeconomic-energy Model. Trans IChemE Part E: Sustainable Production and Consumption, in press, DOI: 10.1016/j.spc.2016.01.003.

$P=0.5^{\text {time step } / \text { half life }}$.

For example, the model operates at 16 time steps per year corresponding to a time-step of $0.0625 \mathrm{y}$. For a half-life of $0.500 \mathrm{y}, P$ would be 0.9170 .

\section{Case study: the UK model}

We demonstrate the dynamic behaviour of a 7see-type model using data for the UK economy over the period 1990-2012. How we condition the data, such as applying a deflator to correct all volume measures back to 1990 prices, is covered in Roberts et al. (2015). The preliminary steps in configuring a country-specific 7see model are detailed in Appendix D along with a list of distinct outputs included in the model. Minimising the number of exogenous variables minimises the amount of configuring, but some country-specific adjustments are needed.

The main steps are to derive the output, production and other coefficients from historical data, and to seed the model with the initial values for $F C$ at $t=0$ (1990 for this case study). The model runs forward in time, creating new values of stocks of $F C$ and outputs. We assess modelling quality by how well it reproduces historical data. In Appendix $\mathrm{E}$ we detail how to set feedback gain for the three larger industries.

\subsection{System-wide dynamics}

In accordance with Eq. (23), we need to make a judgement of the optimal selection of half-life control. For the positive feedback loop, the level of GFCF and unemployment are both sensitive indicators. Unemployment is a small difference of large numbers (the economically active population less jobs provided by all of the industries). Fig. 7 shows a comparison of model-generated data with historical data at time-step resolution for GFCF and unemployment. There are three runs of the model for values of half-life ranging from 0.1 to 0.5 years. We are interested in the model's response for large steps in the historical data.

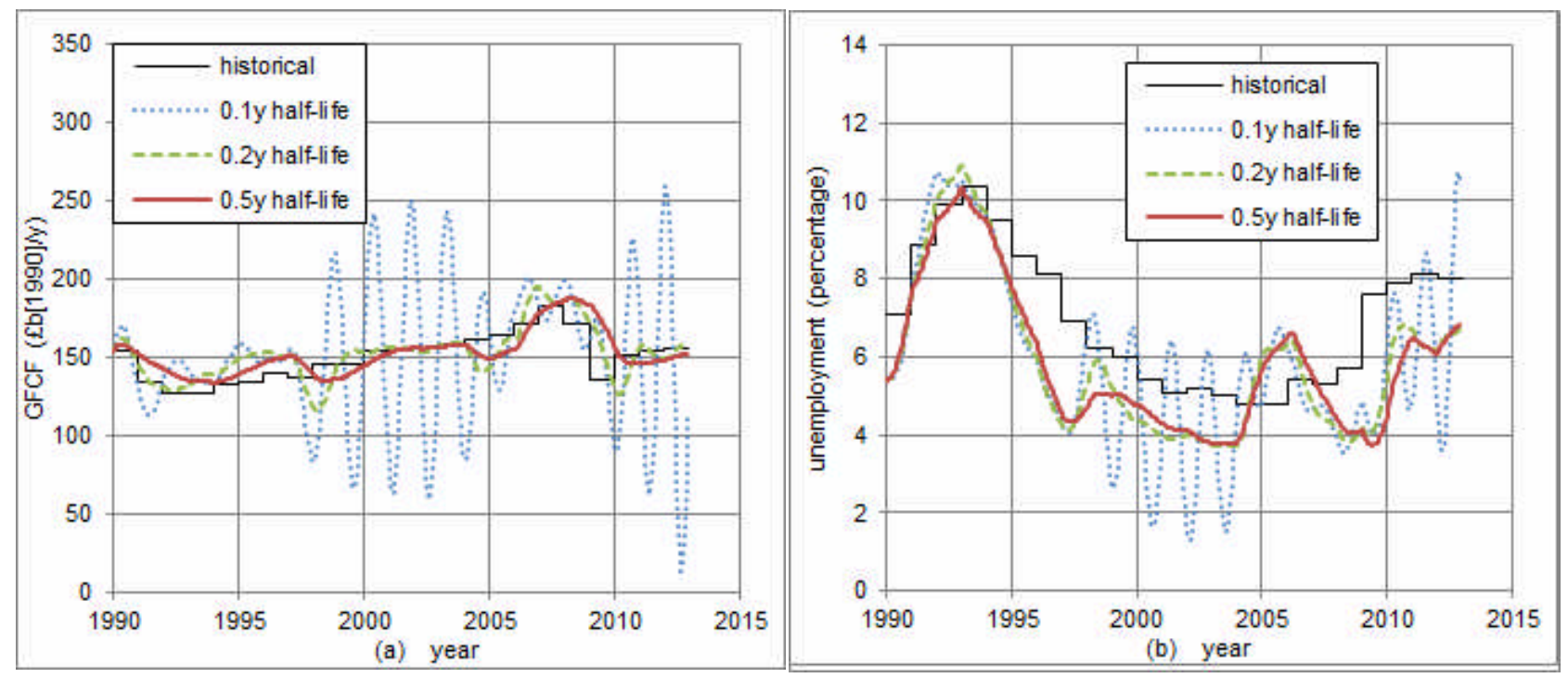

Fig. 7. The performance of feedback at the model time-step resolution (16 steps per year): (a) for GFCF and (b) for unemployment. Both show three values, in years, of control half-life. Data sources: ONS (2014b, 2014c).

At the fast end of the range of $0.1 \mathrm{y}$ half-life, there is a clear susceptibility to oscillations. We are interested in extending the half-life just enough to dampen these oscillations. We conclude that 0.5 years is empirically the best choice. This implies that a demand change in GFCF of $50 \%$ is achieved in 0.5 years and of $90 \%$ in 1.7 years. 
Final version appeared as: SH. Roberts, CJ. Axon, BD. Foran, NH. Goddard, \& BS. Warr (2016). A Robust Data-driven Macro-socioeconomic-energy Model. Trans IChemE Part E: Sustainable Production and Consumption, in press, DOI: 10.1016/j.spc.2016.01.003.

\subsection{Assessing model quality}

The quality of the model can be examined for those of the unique outputs that are model-generated (from feedback control) rather than determined by exogenous demand. This means that we start the model with initial conditions in the first year of historical data. Then allow it to run fully dynamically up to the end of the historical period. CCGT (combined cycle gas turbine) power generation (a stock) in Fig. 8 shows a good match of modelled to historical data.

A further level of assessing model quality can be made by examining the sub-year time response. In response to a new level, we are looking for exponential decay behaviour with a rapid approach. For example, Fig. E.1(c) for FCF of service industry shows a good match. We are not aiming to match the actual levels of the historical data (quantised to years). The key point is that at each step in historical data which shows an abrupt change, data from the model follows this change and settles promptly, within a year, to the new level.

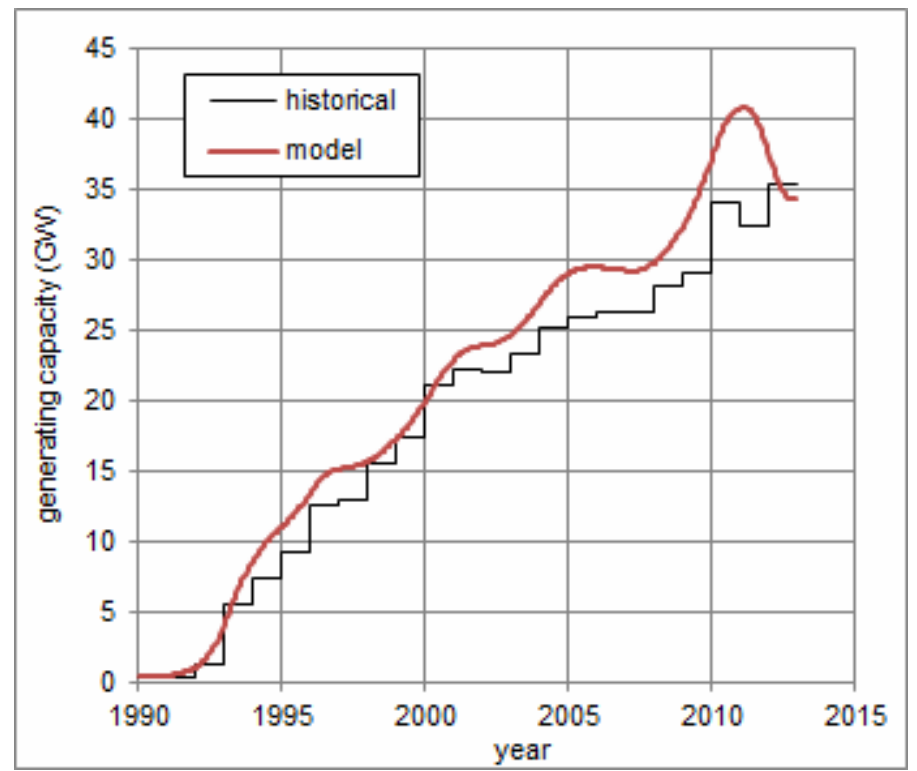

Fig. 8. The performance of feedback for CCGT power generation capacity. (We find that control of this generating capacity from the electricity shortfall is improved by including, at unity gain, an integral term with a decay rate of 5 years.) Data source: DECC (2014).

\section{Conclusions}

A 7see-type model is an explanatory and exploratory computational model of a national macroeconomy. The abstractions used generate insight into the trajectory of the macroeconomy in a new way by breaking down national statistics into a small number of non-substitutable outputs corresponding to physically distinct entities. Our demand-led equilibrium-seeking model suggests that the macroeconomic dynamics are dominated by four main factors: levels of proportional gain representing time constants for varying FCF of manufacturing, construction, and the service industry, and a damping factor of GFCF before it becomes a component of final demand. We have shown explicitly in the model the key role and long-term significance of fixed capital in the evolution of the macroeconomy.

We have shown that the evolution of an economy can be captured with time-dependent output coefficients and production coefficients needing SUT rather than IOT. We examine a given coefficient over the period of historical data to see whether it is rising, constant, declining, or exhibiting a more complicated pattern. For example, if fixed capital for an industry is growing over the historical period and the industry departs from an assumption of constant returns to scale, its output coefficient would vary over time accordingly. The technique of trending coefficients is important for creating a business-as-usual scenario. The coefficients would also be interesting to compare between economies, especially those at different stages of development. However, we note a potential limitation of our use of time-varying coefficients. A single coefficient is not able to distinguish between multiple effects, such as any departure from constant returns to scale, operational improvements, technological change or replacement of old capital with new. 
Final version appeared as: SH. Roberts, CJ. Axon, BD. Foran, NH. Goddard, \& BS. Warr (2016). A Robust Data-driven Macro-socioeconomic-energy Model. Trans IChemE Part E: Sustainable Production and Consumption, in press, DOI: 10.1016/j.spc.2016.01.003.

We have demonstrated that as a dynamic macroeconomic model exploiting feedback control, it reproduces historical data for supply by only initialising the FC of each industry and with a small number of factors that need to be set. While all data is annualised, running a model with 16 sub-year time steps is sufficient to reconcile feedback shortfalls. As long as the rate of calculating feedback is more frequent than the annual steps of historical data, supply $p$ or $f$ is reconciled to demand and tracks it. It is the notion of evolving endogenous variables generated in the model that gives rise to the exploratory power of a 7see-type model. The number of factors to be set is small, thus the effects of assumptions can easily be tracked, making this approach transparent. Key variables remaining as exogenous are final demand of actual final consumption and exports. This means that the model cannot endogenously create economic cycles of booms or recessions. Instead it can only play-out the systemic consequences of variations in final demand and, in particular, the physical constraints to rates of growth.

Compared to computing the Leontief inverse, our iterative approach has a significant advantage when it comes to working with time-series data. Rather than final demand being a static value approached in iterative steps, final demand is time varying. All our coefficients are derived from historical time-series data so are also time series. Our feedback approach not only reconciles industrial production to final demand but follows the time variation of both final demand and coefficients that provide insight into the economy.

The 7see framework and model are intended to be exploratory in that policymakers, academics and others can use them to investigate the likely effects on the macroeconomy of suites of policy choices. For example we expect to apply this model to investigate implications of investment decisions and policies relating to the support and deployment of power generation technologies (whether high or low carbon), energy efficiency policy, and policy support for other low carbon technologies. All scenarios are physically consistent. Although scenarios are not models, the 7 see approach has the capability to inform scenario development as a quantitative tool.

\section{References}

Allan, G., Gilmartin, M., McGregor, P., 2012. Report on the evidence for net job creation from policy support for energy efficiency and renewable energy: An appraisal of multi-sectoral modelling techniques. UKERC, London.

Åström, K.J., Murray, R.M., 2008. Feedback Systems: An Introduction for Scientists and Engineers. Princeton University Press, New Jersey.

Barrett, J., Peters, G., Wiedmann, T., Scott, K., Lenzen, M., Roelich, K., Le Quere, C., 2013. Consumption-based GHG emission accounting: a UK case study. Climate Policy, 13 (4), 451-470.

Battjes J.J., 1999. Dynamic Modelling of Energy Stocks and Flows in the Economy: An Energy Accounting Approach. Ph.D. Thesis, 215 pp. University of Groningen, The Netherlands. http://dissertations.ub.rug.nl/FILES/faculties/science/1999/j.j.battjes/thesis.pdf (accessed 18.09.14.).

Bockermann, A., Meyer, B., Omann, I., Spangenberg, J.H., 2005. Modelling sustainability: comparing an econometric (PANTA RHEI) and a systems dynamic model (SuE). Journal of Policy Modelling 27, 89-210.

Cambridge Econometrics, 2013. Brief Description of MDM-E3. 27 pp. Cambridge. http://www.camecon.com/MacroSectoral/MacroSectoraluk/ModellingCapability/MDME3UKMultisectoralDynamicModel.aspx (accessed 10.02.15).

Cambridge Econometrics, 2014. E3ME Technical Manual Version 6.0. 136 pp. Cambridge. http://www.camecon.com/EnergyEnvironment/EnergyEnvironmentEurope/ModellingCapability/E3ME/E3MEM anual.aspx (accessed 10.02.15).

Capros, P., van Regemorter, D., Paroussos, L., Karkatsoulis, P., Fragkiadakis, C., Tsani, S., Charalampidis, I., Revesz, T., 2013. GEM-E3 Model Documentation. European Commission Joint Research Centre, Institute for Prospective Technological Studies, Seville, Spain. https://ec.europa.eu/jrc/sites/default/files/jrc83177_\%283\%29.pdf (accessed 03.02.15).

Cellier, F.E., 1991. Continuous System Modeling. Springer Verlag, New York.

Cervena, M., Schneider, M., 2014. Short-term forecasting of GDP with a DSGE model augmented by monthly indicators. International Journal of Forecasting, 30 (3), 498-516.

Chang, Y., Ries, R.J., Man, Q.P., Wang, Y.W., 2014. Disaggregated I-O LCA model for building product chain energy quantification: A case from China. Energy and Buildings, 72, 212-221.

Chu, B., Duncan, S., Papachristodoulou, A., 2011. A Model for Using Control Theory to Design Sustainable Policies for Greenhouse Gas Emissions. IEEE International Conference on Control Applications (CCA), September 28-30, Denver, USA. 
Final version appeared as: SH. Roberts, CJ. Axon, BD. Foran, NH. Goddard, \& BS. Warr (2016). A Robust Data-driven Macro-socioeconomic-energy Model. Trans IChemE Part E: Sustainable Production and Consumption, in press, DOI: 10.1016/j.spc.2016.01.003.

Chu, B., Duncan, S., Papachristodoulou, A., Hepburn, C., 2013. Analysis and control design of sustainable policies for greenhouse gas emissions. Applied Thermal Engineering 53 (2), 420-431.

Coyle, R.G., 2001. Systems Dynamics Modelling: A Practical Approach. Chapman and Hall/CRC, London.

Crane, D.C., 1996. Balancing pollutant emissions and economic growth in a physically conservative world. Ecological Economics 16 (3), 257-268.

Dale, M., Krumdieck, S., Bodger, P., 2012a. Global energy modelling — A biophysical approach (GEMBA) part 1: An overview of biophysical economics. Ecological Economics 73 152-157.

Dale, M., Krumdieck, S., Bodger, P., 2012b. Global energy modelling - A biophysical approach (GEMBA) Part 2: Methodology. Ecological Economics 73, 158-167.

DECC, 2014. Digest of UK energy statistics (DUKES). Department of Energy and Climate Change, London. http://www.gov.uk/government/organisations/department-of-energy-climate-change/series/digest-of-uk-energystatistics-dukes (accessed 21.04.15).

Dixon, P.B., Rimmer, M.T., 2002. Dynamic general equilibrium modelling for forecasting and policy: a practical guide and documentation of MONASH. North-Holland, Amsterdam.

Duarte, R., Mainar, A., Sanchez-Choliz, J., 2013. The role of consumption patterns, demand and technological factors on the recent evolution of $\mathrm{CO} 2$ emissions in a group of advanced economies. Ecological Economics, 96, 1-13.

Foran, B., 2011. Low carbon transition options for Australia. Ecological Modelling, 223 (1), 72-80.

Foran, B., Crane, D., 1998. The OzECCO embodied energy model of Australia's physical economy. In: Advances in Energy Studies: Energy Flows in Ecology and Economy, Porto Venere, May 26-30, 579-596.

Forrester, J.W., Mass, N.J., Ryan, C.J., 1976. The system dynamics national model: Understanding socio-economic behavior and policy alternatives. Technological Forecasting and Social Change. 9 (1-2), 51-68.

Forrester J.W., 2007. System Dynamics: A Personal View of the First Fifty Years. System Dynamics Review, 23 (2/3), 345-358.

Forrester, J.W., 2013. Economic theory for the new millennium (2003). System Dynamics Review, 29 (1) 26-41.

Golosov, M., Hassler, J., Krusell, P., Tsyvinski, A., 2014. Optimal taxes on fossil fuel in general equilibrium. Econometrica, 82 (1), 41-88.

Harrison, G.W., Hougaard Jensen, S.E., Pedersen, L., Rutherford, T.F., 2000. Using dynamic general equilibrium models for policy analysis. North-Holland, Amsterdam.

Harvey, J.T., 2013. Keynes's trade cycle: a system dynamics model. Journal of Post Keynesian Economics, 36 (1), $105-$ 130.

Hayward, J., Boswell, G,P., 2014. Model behaviour and the concept of loop impact: A practical method. System Dynamics Review, 30, 29-57.

HM Treasury, 2013. National Infrastructure Plan. HM Treasury, London.

IMF, 2011. Balance of Payments and International Investment Position Manual, Sixth Edition. International Monetary Fund, Washington D.C. http://www.imf.org/external/pubs/ft/bop/2007/bopman6.htm (accessed 05.10.14).

John K.D., 2012. Linking Economic Modeling and System Dynamics: A Basic Model for Monetary Policy and Macroprudential Regulation. 30th International Conference of the System Dynamics Society, July 22-26, St. Gallen, Switzerland.

Kelly (Letcher), R.A., Jakeman, A.J., Barreteau, O., Borsuk, M.E., ElSawah, S., Hamilton, S,H., Henriksen, H.J., Kuikka, S., Maier, H.R., Rizzoli, A.E., van Delden, H,, Voinov, A,A., 2013. Selecting among five common modelling approaches for integrated environmental assessment and management. Environmental Modelling and Software, 47, 159-181.

Kratena, K., Streicher, G., Temurshoev, U., Amores, A.F., Arto, I., Mongelli, I., Neuwahl, F., Rueda-Cantuche, J.M., Andreoni. V., 2013. FIDELIO 1: Fully Interregional Dynamic Econometric Long-term Input-Output Model for the EU27. European Commission Joint Research Centre, Institute for Prospective Technological Studies, Seville, Spain. http://ftp.jrc.es/EURdoc/JRC81864.pdf (accessed 03.02.15).

Lecca, P., McGregor, P.G., Swales, J.K., 2013. Forward-looking and myopic regional Computable General Equilibrium models: How significant is the distinction? Economic Modelling, 31, 160-176.

LeCoq, F., Shalizi, Z., 2014. The economics of targeted mitigation in infrastructure. Climate Policy 14 (2), $187-208$.

Lejour, A.M., Veenendaal, P., Verweij, G., van Leeuwen, N.I.M., 2006. WorldScan: a model for International Economic Policy Analysis. Document 111. CPB Netherlands Bureau for Economic Policy Analysis, The Hague, The Netherlands. $\quad$ http://www.cpb.nl/en/publication/worldscan-model-international-economic-policy-analysis (accessed 17.02.15).

Lenzen, M., Reynolds, C.J., 2014. A Supply-Use Approach to Waste Input-Output Analysis. Journal of Industrial Ecology, 18 (2), 212-226. 
Final version appeared as: SH. Roberts, CJ. Axon, BD. Foran, NH. Goddard, \& BS. Warr (2016). A Robust Data-driven Macro-socioeconomic-energy Model. Trans IChemE Part E: Sustainable Production and Consumption, in press, DOI: 10.1016/j.spc.2016.01.003.

Lutz, C., Meyer, B., Wolter, M.I. 2010. The Global Multisector/Multicountry 3E-Model GINFORS: A Description of the Model and a Baseline Forecast for Global Energy Demand and CO2 Emissions. International Journal of Global Environmental Issues, 10 (1-2), 25-45.

McGregor, P.G., Swales, J.K., Turner, K., 2008. The CO2 'trade balance' between Scotland and the rest of the UK: Performing a multi-region environmental input-output analysis with limited data. Ecological Economics, 66 (4), $662-673$.

Marcellino, M., Rychalovska, Y., 2014. Forecasting with a DSGE Model of a Small Open Economy within the Monetary Union. Journal of Forecasting, 33 (5), 315-338.

Meadows, D.H., Meadows, D.L., Randers J., Behrens, W.W., 1972. The Limits to Growth. Potomac, New York.

Meyer, B., 2005. The economic environmental model PANTA RHEI and its application. Congress of Environment and Science - Concepts and Strategic Goals for the Future, April 9-11 Tokyo.

Mollerup, A.L., Mikkelsen, P.S., Thornberg, D., Sin, G.., 2015. Regulatory control analysis and design for sewer systems. Environmental Modelling and Software, 66, 153-166.

Noorman, K.J., 1995. Exploring futures from an energy perspective: A natural capital accounting model study into the long-term economic development potential of the Netherlands. Ph.D. Thesis University of Groningen, The Netherlands. http://dissertations.ub.rug.nl/faculties/science/1995/k.j.noorman/ (accessed 18.09.14.).

ONS, 2006. Business investment Revised results - 3rd quarter 2006. Office for National Statistics, Newport. http://www.ons.gov.uk/ons/rel/bus-invest/business-investment/q3-2006---revised-results/index.html (accessed 28.10.14).

ONS, 2012a. United Kingdom National Accounts - The Blue Book, 2012 Edition. Office for National Statistics, Newport. http://www.ons.gov.uk/ons/rel/naa1-rd/united-kingdom-national-accounts/index.html (accessed 05.10.14).

ONS, 2012b. Input-Output Supply and Use Tables 2012 Edition. Office for National Statistics, Newport. http://www.ons.gov.uk/ons/rel/input-output/input-output-supply-and-use-tables/index.html (accessed 05.10.14).

ONS, 2012c. United Kingdom Balance of Payments - The Pink Book, 2012 Edition. Office for National Statistics, Newport. http://www.ons.gov.uk/ons/rel/bop/united-kingdom-balance-of-payments/2012/index.html (accessed 05.10.14).

ONS, 2014a. Annual Gross Fixed Capital Formation 1997-2013, by Industry and Asset. Office for National Statistics, Newport. http://www.ons.gov.uk/ons/publications/re-reference-tables.html?edition=tcm\%3A77-325825 (accessed 25.10.14).

ONS, 2014b. United Kingdom National Accounts - The Blue Book, 2014 Edition. Office for National Statistics, Newport. http://www.ons.gov.uk/ons/rel/naa1-rd/united-kingdom-national-accounts/the-blue-book--2014edition/index.html (accessed 21.04.15).

ONS, 2014c. Labour Market Statistics, November 2014. Office for National Statistics, Newport. http://www.ons.gov.uk/ons/rel/lms/labour-market-statistics/november-2014/statistical-bulletin.html (accessed 21.04.15).

Radzicki, M.J., 1988. Institutional Dynamics: An Extension of the Institutionalist Approach to Socioeconomic Analysis. Journal of Economic Issues, 22 (3), 633-666.

Richardson, G.P., 2011. Reflections on the foundations of system dynamics. Systen Dynamics Review, 27 (3), $219-243$.

Roberts, P.C., 1978. Modelling large systems: Limits to Growth Revisited. Taylor and Francis, London.

Roberts, S.H, Axon, C.J., Foran, B.D., Goddard, N.H., Warr, B.S., 2015. A framework for characterising an economy by its energy and socio-economic activities. Sustainable Cities and Society, 14, 99-113.

Ryan, G.J., 1995. Dynamic Physical Analysis of Long-term Economy-Environment Options. Ph.D. Thesis, 308 pp, University of Canterbury, New Zealand. http://ir.canterbury.ac.nz/handle/10092/4375 (accessed 10.02.15).

Schembri, P., 1999. Adaptation costs for sustainable development and ecological transitions: a presentation of the structural model M3ED with reference to French energy-economy-carbon dioxide emission prospects. International Journal of Environment and Pollution, 11 (4), 542-564.

Spangenberg, J., Hinterberger, F., Scharnagl, A., Mündl, A., Klingert, S., Schütz, H., Fleßner, A., King, J., Slesser, M., Crane, D., Essling, R., Barnes, R., Luukkanen, J., Peltola, T., Rivas, D.M., Alferez, A., Cabezudo, S., Pérez, M., Rodriguez, J., 1998. Modelling a socially and environmentally sustainable Europe. Final report of the EU funded research project no. TSER-SOE1-CT96-1018. Wuppertal. http://cordis.europa.eu/publication/rcn/6712_en.html (accessed 16.02.15).

Shoven, J.B., Whalley, J., 1992. Applying general equilibrium. Cambridge Uninersity Press, Cambridge.

Slesser, M., King, J., 1988. Resource accounting: an application to development planning. World Development 16, $293-$ 303.

Slesser, M., King, J., Crane, D.C., Revie, C., 1994a. UKECCO Technical User's Manual, Vol. I. Centre for Human Ecology, University of Edinburgh. 
Final version appeared as: SH. Roberts, CJ. Axon, BD. Foran, NH. Goddard, \& BS. Warr (2016). A Robust Data-driven Macro-socioeconomic-energy Model. Trans IChemE Part E: Sustainable Production and Consumption, in press, DOI: 10.1016/j.spc.2016.01.003.

Slesser, M., King, J., Crane, D.C., Revie, C., 1994b. UKECCO Technical User's Manual, Vol. II. Centre for Human Ecology, University of Edinburgh.

Slesser, M., King, J., Crane, D.C., Barnes, R., Essling, R., 1998. Evolutionary policies for a sustainable Europe. Edinburgh: Institute of Ecology and Resource Management, University of Edinburgh.

Sterman, J.D., 2000. Business Dynamics: Systems Thinking and Modeling for a Complex World. McGraw-Hill, Boston.

United Nations. 2008a. International standard industrial classification of all economic activities revision 4. Statistical Papers Series M No.4/Rev.4. United Nations, New York.

United Nations. (2008b). The Central Product Classification (CPC) Ver.2. United Nations, NewYork.. http://unstats.un.org/unsd//cr/registry/cpc-2.asp (accessed 18.09.14).

United Nations, European Commission, International Monetary Fund, Organisa-tion for Economic Co-operation and Development, and World Bank. (2009). System of national accounts 2008. United Nations, New York.. http://unstats.un.org/unsd/nationalaccount/sna2008.asp (accessed 18.09.14).

Victor, P.A. Rosenbluth, G., 2007. Managing without growth. Ecological Economics, 61 (2-3), 492-504.

Zagamé, P., Boitier, B., Fougeyrollas, A., Le Mouël, P., Capros, P., Kouvaritakis, N., Bossier, F., Thierry, F., Melon A., 2010. The NEMESIS Reference Manual. Seureco Erasme, Paris. http://www.erasmeteam.eu/files/Manual_Part_I.pdf (accessed 04.02.15).

\section{Acknowledgements}

We are grateful for graphical design of the diagrams by Elisa Magnini and Mark Pearsall in the Arup Foresight group. We would like to thank Dr. Kim Parker of the University of Kent, Chris Thoung of CentreForum and Prof. Klaus Hasselmann for very useful discussions, and the anonymous reviewers for their helpful comments. This work was supported financially by Arup's internal Design and Technical Fund.

\section{Appendix A: Data from Supply and Use Tables}

\section{A.1 Statement of product balance}

We use the national accounts (ONS, 2012a) and the SUT (ONS, 2012b) formalism with reference to example data in Fig. A.1. In this example, we have reduced the original list in the source data from 10 products and industries down to six according to Table 1 by combining rows and columns as appropriate. We explicitly note that services includes rental that we denote by serv $I R$ since we associate rental with dwellings in Table 1. The finer detail of 97 industries is necessary to disaggregate production of extr+manu+util in order to arrive at the 7see set of six industries. Furthermore, the finer resolution is needed to separate rental, from serv, needed for Fig. A.2.

A key feature of the SNA is the statement of product balance (United Nations et al., 2009). For each product $i$ available for use in the economy,

Output + Imports $=$ Intermediate Consumption + Final Consumption + Capital Formation + Exports

This corresponds to each row of a SUT (Fig. A.1) where the values are exactly matched comparing columns 5 (the sum of Supply Table rows) to column 24 (the sum of Use Table rows). Columns 18-20 correspond to Final Consumption in the product balance above.

Intermediate consumption (IC) is an accounting principal which consists of the total monetary value of goods and services consumed in production, including raw materials, services and various other operating expenses. In Use Table Fig. A.1(b), columns 11 to 16 take an industry-based view of output. Each number represents the value of the product given in the row that is used by the industry given in the column. So in Fig. A.1(b), agri uses $£ 443 \mathrm{~m}$ of util products. Row 17 over columns 11 to 16 is the total IC of each industry. Adding the value-added for each industry in row 18 gives the total output of each industry in row 19. The total output is the same whether summed over products or industries: the bottom of the Supply Table column 1 for the sum by products of $£ 2,669,188 \mathrm{~m}$ is the same as the end of the Use Table row 19 (column 17), which is the sum by industries. 
Final version appeared as: SH. Roberts, CJ. Axon, BD. Foran, NH. Goddard, \& BS. Warr (2016). A Robust Data-driven Macro-socioeconomic-energy Model. Trans IChemE Part E: Sustainable Production and Consumption, in press, DOI: 10.1016/j.spc.2016.01.003.

\begin{tabular}{|c|c|c|c|c|c|c|}
\hline & & 1 & 2 & 3 & 4 & 5 \\
\hline & Supply & $\begin{array}{l}\text { Domestic } \\
\text { output of } \\
\text { products at } \\
\text { basic prices }\end{array}$ & $\begin{array}{l}\text { Import of } \\
\text { goods and } \\
\text { services }\end{array}$ & $\begin{array}{l}\text { Distributors' } \\
\text { trading } \\
\text { margins }\end{array}$ & $\begin{array}{l}\text { Taxes less } \\
\text { subsidies on } \\
\text { products }\end{array}$ & $\begin{array}{c}\text { Total supply } \\
\text { of products at } \\
\text { purchasers' } \\
\text { prices }\end{array}$ \\
\hline & products $i$ & $\mathrm{O}+$ & $M+$ & $\mathrm{U}+$ & $T+$ & TS \\
\hline 1 & agri & 21,462 & 9,501 & 5,664 & 201 & 36,828 \\
\hline 2 & extr & 45,763 & 34,087 & 3,764 & 427 & 84,041 \\
\hline 3 & util & 91,772 & 411 & 0 & 2,334 & 94,517 \\
\hline 4 & manu & 403,146 & 328,508 & 232,022 & 92,915 & $1,056,591$ \\
\hline 5 & cnstr & 208,733 & 1,360 & 0 & 15,638 & 225,731 \\
\hline 6 & serv IR & $1,898,312$ & 105,520 & $-241,450$ & 46,092 & $1,808,474$ \\
\hline 7 & $\begin{array}{l}\text { sum over } \\
1-6\end{array}$ & $2,669,188$ & 479,387 & 0 & 157,607 & $3,306,182$ \\
\hline
\end{tabular}

(a)

\begin{tabular}{|c|c|c|c|c|c|c|c|c|c|c|c|c|c|c|c|}
\hline & \multirow[b]{2}{*}{ Use } & 11 & 12 & 13 & 14 & 15 & 16 & \multirow{2}{*}{$\begin{array}{c}17 \\
\text { Total IC } \\
@ b p\end{array}$} & \multirow{2}{*}{$\begin{array}{c}18 \\
\text { House- } \\
\text { holds }\end{array}$} & \multirow{2}{*}{$\begin{array}{c}19 \\
-\mathrm{NPISHs}\end{array}$} & \multirow{2}{*}{$\begin{array}{c}20 \\
\text { General } \\
\text { government } \\
\text { final } \\
\text { consumption }\end{array}$} & \multirow{2}{*}{$\begin{array}{c}21 \\
\text { Gross } \\
\text { capital } \\
\text { formation }\end{array}$} & \multirow{2}{*}{$\begin{array}{c}22 \\
\text { Exports of } \\
\text { goods and } \\
\text { services }\end{array}$} & \multirow{2}{*}{$\begin{array}{c}23 \\
\begin{array}{c}\text { Final } \\
\text { demand } \\
@ p p\end{array}\end{array}$} & \multirow{2}{*}{$\frac{24}{\text { Total }}$} \\
\hline & & & Inter & $\begin{array}{r}\text { rmediate } \\
\text { indu }\end{array}$ & $\begin{array}{l}\text { consumpt } \\
\text { ustries } j\end{array}$ & tion (IC) & & & & & & & & & \\
\hline & products $i$ & agri + & extr + & util + & $\operatorname{manu}+$ & cnstr + & serv IR & $=11$ to 16 & $\mathrm{H}+$ & $\mathrm{N}+$ & GG + & GCF + & $x$ & FD & $=17+23$ \\
\hline 11 & agri & 2,762 & 1 & 10 & 12,063 & 228 & 1,786 & 16,850 & 16,305 & 0 & 0 & 987 & 2,686 & 19,978 & 36,828 \\
\hline 12 & extr & 0 & 6,275 & 29,167 & 22,075 & 2,258 & 323 & 60,098 & 242 & 0 & 0 & 360 & 23,341 & 23,943 & 84,041 \\
\hline 13 & util & 443 & 531 & 25,726 & 10,999 & 713 & 13,126 & 51,538 & 42,698 & 0 & 0 & 1 & 280 & 42,979 & 94,517 \\
\hline 14 & manu & 6,809 & 3,483 & 6,415 & 192,957 & 31,840 & 165,624 & 407,128 & 351,313 & 0 & 0 & 63,607 & 234,543 & 649,463 & $1,056,591$ \\
\hline 15 & cnstr & 370 & 1,247 & 978 & 2,257 & 60,103 & 38,233 & 103,188 & 7,103 & 0 & 0 & 113,940 & 1,500 & 122,543 & 225,731 \\
\hline 16 & $\operatorname{serv} \mathbb{I R}$ & 3,005 & 5,132 & 5,926 & 51,026 & 29,441 & 626,895 & 721,425 & 486,298 & 37,578 & 335,040 & 42,598 & 185,535 & $1,087,049$ & $1,808,474$ \\
\hline 17 & $\begin{array}{l}\text { sum over } \\
11-16\end{array}$ & 13,389 & 16,669 & 68,222 & 291,377 & 124,583 & 845,987 & $1,360,227$ & 903,959 & 37,578 & 335,040 & 221,493 & 447,885 & $1,945,955$ & $3,306,182$ \\
\hline 18 & GVA & 8,333 & 32,211 & 28,712 & 141,711 & 83,280 & $1,014,714$ & $1,308,961$ & & & & & & & \\
\hline 19 & $\begin{array}{l}\text { Output } \\
\text { @bp }\end{array}$ & 21,722 & 48,880 & 96,934 & 433,088 & 207,863 & $1,860,701$ & $2,669,188$ & & & & & & & \\
\hline
\end{tabular}
(b)

Fig. A.1. Example data for SUT (UK data for 2010 in millions of pounds at current prices). Columns in boxes are totals. Column 1 is also boxed for comparison to column 17. (a) Supply Table. (b) Use Table. For definition of the products i, see Table 1. (@bp: at basic prices).

\section{A.2 Production coefficient and the Leontief inverse}

Production coefficients are used for the values in the IC part of a Use Table (columns 11-16 by rows 11-16) forming matrix $A$ in Table A.1. Each coefficient $a_{i j}$ of matrix $A$ indicates the amount of $i^{\text {th }}$ s products (the rows) needed to produce one unit of $\mathrm{j}^{\text {th }}$ s product (the columns). Matrix $A$ of $\mathrm{a}_{\mathrm{ij}}$ is also sometimes called a matrix of technological coefficients (United Nations et al., 2009) and can provide insights into the way an economy works. As an economy develops, the processing of primary products becomes more commonplace, thus matrix $A$ becomes populated with entries reflecting greater vertical and horizontal integration of activities within the economy.

Table A.1. The standard matrix $A$ of production coefficients $\mathrm{a}_{\mathrm{ij}}$, as derived from the IC part of Fig. A.1(b) by dividing by output@bp.

\begin{tabular}{lllllll}
\hline \multirow{2}{*}{ Products $\boldsymbol{i}$} & Industries $\boldsymbol{j}$ & \multicolumn{1}{c}{} & & & \\
\cline { 2 - 7 } & agri & extr & util & manu & cnstr & serv IR \\
\hline agri & 0.13 & 0.00 & 0.00 & 0.03 & 0.00 & 0.00 \\
util & 0.00 & 0.13 & 0.30 & 0.05 & 0.01 & 0.00 \\
manu & 0.02 & 0.01 & 0.27 & 0.03 & 0.00 & 0.01 \\
cnstr & 0.31 & 0.07 & 0.07 & 0.45 & 0.15 & 0.09 \\
serv $\boldsymbol{I R}$ & 0.02 & 0.03 & 0.01 & 0.01 & 0.29 & 0.02 \\
\hline
\end{tabular}


Final version appeared as: SH. Roberts, CJ. Axon, BD. Foran, NH. Goddard, \& BS. Warr (2016). A Robust Data-driven Macro-socioeconomic-energy Model. Trans IChemE Part E: Sustainable Production and Consumption, in press, DOI: 10.1016/j.spc.2016.01.003.

A problem arises with these production coefficients $a_{i j}$ if, given values of final demand for each product (column 24), we want to calculate the total output of each industry (row 19) necessary to meet this demand. A single product needs multiple, different inputs. The consequent increase in direct demand has ripple effects (indirect demand) further up the supply chains.

The Leontief inverse addresses this issue by appropriate inversion of the matrix of all $\mathrm{a}_{\mathrm{ij}}$. If $A$ is the matrix of coefficients, $I$ the identity matrix, $x$ the vector of outputs, and $y$ the vector of total final demand, then

$$
\begin{aligned}
& y=(I-A) \cdot x, \text { thus } \\
& x=(I-A)^{-1} \cdot y
\end{aligned}
$$

The matrix $(I-A)$ is the Leontief matrix and $(I-A)^{-1}$ the Leontief inverse matrix of $b_{\mathrm{ij}}$. Each Leontief coefficient $b_{i j}$ indicates the contribution of industry $j$ needed for one unit of product $i$ of final demand. This formulation requires matrix A to be square, which means that SUTs must be manipulated to form IOTs because of secondary products (companies usually produce multiple products).

To derive a product-by-product matrix, the IC and value added parts of the matrix need to be changed from an industry dimension to a product one. As the row totals of the matrix have the correct product totals, entries are simply reallocated between columns within the given row total. To derive an industry-by-industry matrix, items need to be allocated between rows (not columns).

\section{A.3 Goods and services account for GDP}

National statistics offices are more likely to have a continuous series of SUTs than IOT data with Leontief inverses which are often available only for occasional years. As the 7 see proposition is to be data-driven and comprehensive over an historical period, it needs to work with SUT alone without depending on infrequent IOT data.

The total output of each industry is a key aspect of how the SUT are arranged (Use Table, row 19) as well as the denominator for production coefficients $\mathrm{a}_{\mathrm{ij}}$. However, we suggest that rather than working with the total output of industry, these data can be reconfigured for a focus on GVA (Use Table, row 18). We observe in other areas that GVA is either the numerator, as in labour productivity, or the denominator for the intensity of use of an input for production, such as electricity or water.

The sum of all product balances may be rearranged to become the goods and services account (United Nations et al., 2009):

Output - Intermediate Consumption + Taxes on Products - Subsidies on Products $=$ Final Consumption + Capital Formation + Exports - Imports

The left-hand side of the identity is the 'production approach' to GDP (at market prices) while the right-hand side is the 'expenditure approach'. Making use of GDP at basic prices, we can rearrange the goods and services account as:

$$
\text { GDP at Basic Prices }+ \text { Imports }=\text { Final Demand }-(\text { Taxes on Products }- \text { Subsidies on Products })
$$

Using the example data in Fig. A.1, we can explain in Fig. A.2 how we can work with the sum of GDP-atbasic-prices plus imports which we now express as $G D P_{b a s i c}+M$.

We separate rental from services, as denoted by serv LR (Table 1) because we associate the products with their FC, thus rental should be associated with dwellings, not the FC of service industry. Our 7see formulation table (Fig. A.2) from GVA to final demand is a series of four sub-totals which are each obtained by adding values on progressing from left to right. 
Final version appeared as: SH. Roberts, CJ. Axon, BD. Foran, NH. Goddard, \& BS. Warr (2016). A Robust Data-driven Macro-socioeconomic-energy Model. Trans IChemE Part E: Sustainable Production and Consumption, in press, DOI: 10.1016/j.spc.2016.01.003.

To build our 7see reformulation we start on the right in Fig. A.3(c), with columns 20 and 21, of taxes from the Supply Table (Fig. A.1, column 4) and final demand from the Use Table (Fig. A.1, column 23). By subtracting taxes from FD, we obtain the quantity in column 19 of $G D P_{\text {basic }}+M$. Its total is $£ 1,788,348 \mathrm{~m}$ which, progressing to the left, is maintained in columns 17 and 4 . We denote all of these columns by supply types $q+M, r$ and $s$ (columns $4,17,19$ ). We introduce in column 3 imports $M$ which, when subtracted from column 4 , gives GDP (supply type $q$ ) in column 2 of $£ 1,308,961 \mathrm{~m}$. This same total is shown for the more usual form of GDP by the production approach of valued added or GVA in column 1 (supply type $p$ ).

We now explain the relationships between supply types $q+M, r$ and $s$. The distributors' details (known in the SNA as transport and trade margins) in column 18 are from the Supply Table (column 3). These sum to zero since they are a reassignment of services from the serv $L R$ row to those products for which these services are incorporated into their market prices to consumers of final demand. Supply $r$ (column 17) equals supply $s$ (column 19) less distribution costs (column 18).

All of columns 5 to 16 cover the processing for IC. The left half, columns 5-10, is the same as in the Use Table (columns 11-16) but with diagonal values removed and all values set to minus (to represent the fact that this amount is received by the industry given in the column from the industry given in the row). Suppose we start with a supply of products in column 4, their supply for IC means their rate is reduced by adding the negative values. Now we reach one of the key differences between SUT and the 7see reformulation. In 7see we add into a row the concept of the consuming industry of IC which is handled in a row rather than a column. The matrix in columns 5 to 10 is transposed and set to positive for columns 11 to 16. Supply $q+M$ (column 4 ) is column 17 less columns 5 to 16 . Supply $q+M$ could be considered as the pure component of value added by each industry and imports. Supply $r$ (column 17) is after IC could be considered as products approaching their final form ready for final demand.

We describe overall what Fig. A.2 represents. Column 1 is GVA data of products $p$ as categorized by industry, as in row 19 of the Use Table. From column 2 on to the right, each row is categorized by products starting with $q$ evolving to products $f$. Note that column 2 is derived by starting with final demand in column 21 and working back to the left by progressive subtraction. We introduce the 7see formulation of coefficients (Fig. A.3). Our purpose is to use ratios (coefficients) for the complete connection from GVA by industries in Fig. A.2(a) column 1 to final demand by products in Fig. A.2(c) column 21. Furthermore, all of these coefficients can provide insights into the way an economy works. 
Final version appeared as: SH. Roberts, CJ. Axon, BD. Foran, NH. Goddard, \& BS. Warr (2016). A Robust Data-driven Macro-socioeconomic-energy Model. Trans IChemE Part E: Sustainable Production and Consumption, in press, DOI: 10.1016/j.spc.2016.01.003.

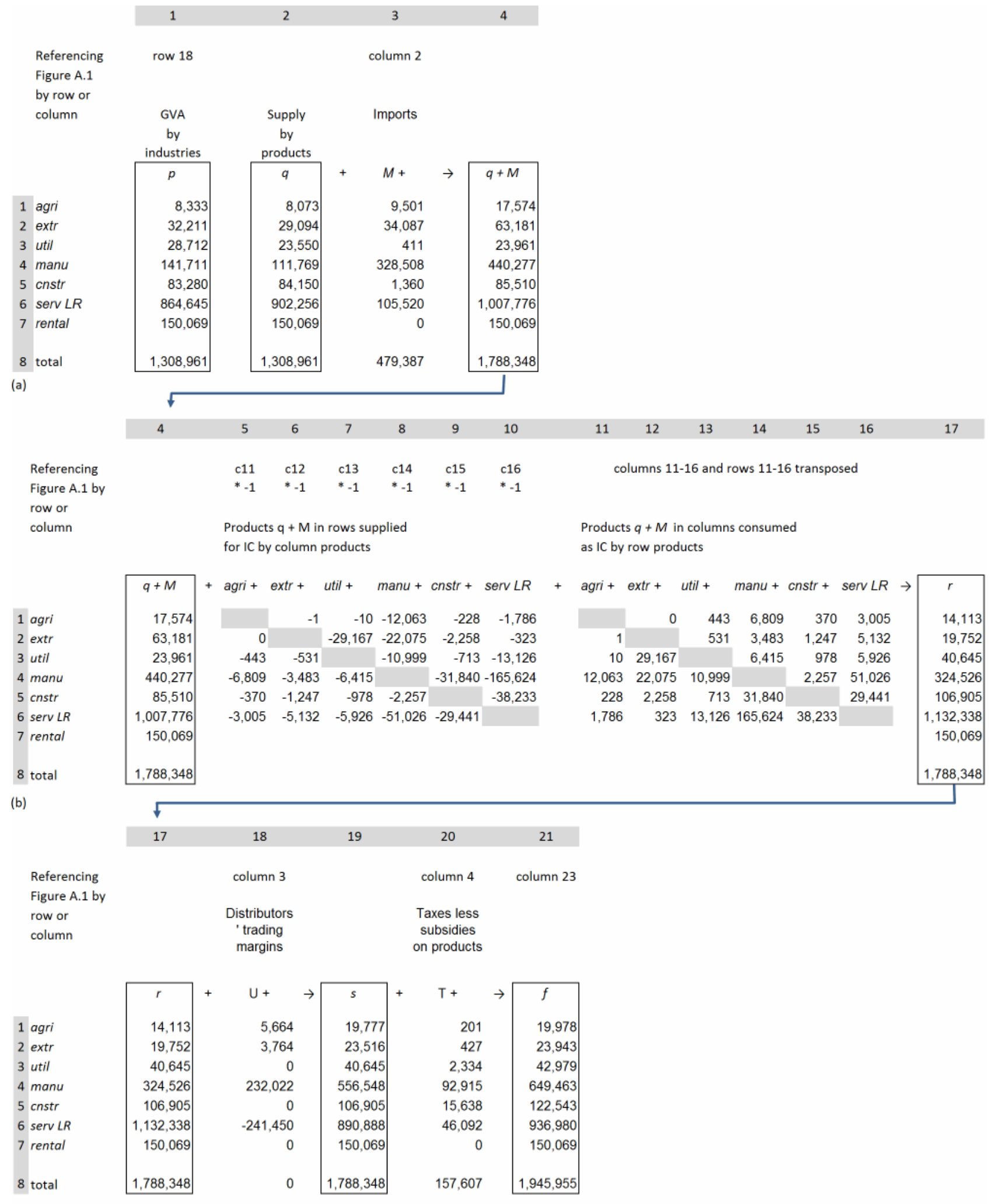

(c)

Fig. A.2. Data from Fig. A.1 in the 7see reformulation. Data from Fig. A.1 are identified by row and column (c..) referencing. Columns in boxes are sub-totals. (a) columns 1 to 4 for products $p, q$ and $q+M$, (b) columns 4 to 17 for products $q+M$ and $r$ following IC, (c) columns 17 to 21 for products $r, s$ and $f$. 
Final version appeared as: SH. Roberts, CJ. Axon, BD. Foran, NH. Goddard, \& BS. Warr (2016). A Robust Data-driven Macro-socioeconomic-energy Model. Trans IChemE Part E: Sustainable Production and Consumption, in press, DOI: 10.1016/j.spc.2016.01.003.

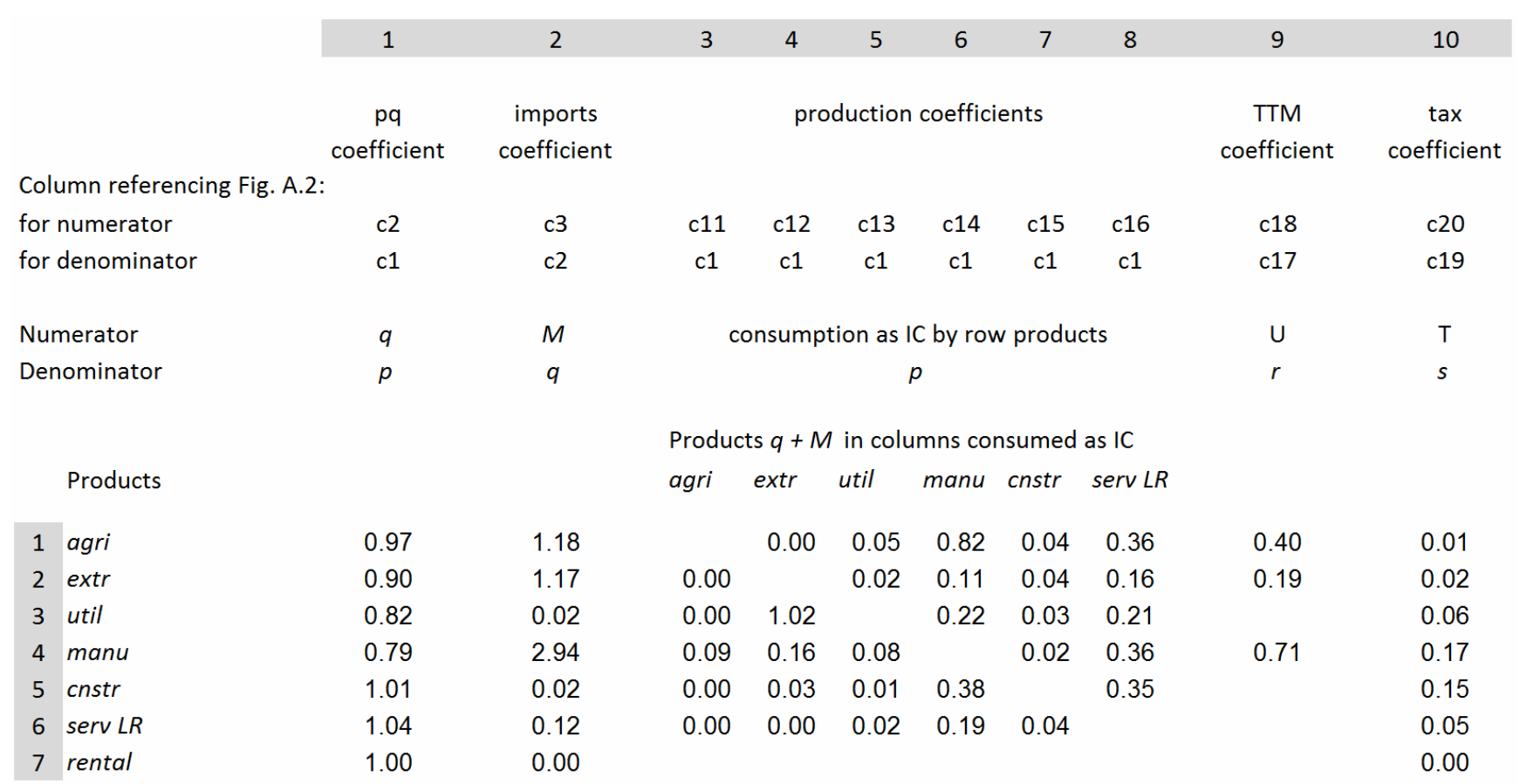

Fig. A.3. The coefficients derived from the values in Fig. A.2. Data from Fig. A.2 are identified by column (c..) referencing.

Starting on the left in Fig. A.3, the first coefficient (column 1) multiplies GVA by industry $p$ to reach categorization by product $q$ (pq coefficient). This is equivalent to the SNA reassigning of secondary products. The next coefficient (column 2) is the ratio of imports by product to supply $q$ (imports coefficient). Moving to IC, we derive coefficients only for consumption (production coefficients), not supply, which are in Fig. A.2(c), columns 11-16. These coefficients (Fig. A.3, columns 3 to 8) can be interpreted as the intensity of supply of one product (the column) according to the GVA of another product (the row).

For distributors' margin (referred to as transport and trade margins in the SNA) in Fig. A.2(c) column 18, a more appropriate denominator than GVA is supply $r$, after IC, forming the 7see TTM coefficient. This follows from the idea that traders' mark-up is in proportion to their buy-in price (the margin). For column 20 of (net) taxes on products, the appropriate denominator is the value of products at basic prices, supply $s$, as it would correspond to the case of value-added tax (tax coefficient). 
Final version appeared as: SH. Roberts, CJ. Axon, BD. Foran, NH. Goddard, \& BS. Warr (2016). A Robust Data-driven Macro-socioeconomic-energy Model. Trans IChemE Part E: Sustainable Production and Consumption, in press, DOI: 10.1016/j.spc.2016.01.003.

\section{Appendix B: Finite Time-step Computational Sequence for a Single Infrastructure Module}

We detail here the computational sub-steps for one full time-step of the module in Fig. 2(b) showing how stocks of FC evolve. We summarise these sub-steps graphically in Fig. B.1.

\begin{tabular}{|c|c|c|c|c|c|c|c|c|c|c|}
\hline & \multirow{2}{*}{$\begin{array}{c}\text { Stock } \\
\alpha \\
\end{array}$} & \multicolumn{2}{|c|}{ Flows } & \multirow{2}{*}{\begin{tabular}{|c|} 
Supply \\
$\delta$ \\
\end{tabular}} & \multirow{2}{*}{\begin{tabular}{|c|} 
Control \\
shortfall \\
\end{tabular}} & \multicolumn{2}{|c|}{ Demand } & \multirow{2}{*}{$\begin{array}{c}\text { Supply } \\
\eta\end{array}$} & \multirow{2}{*}{$\begin{array}{c}\text { Stock } \\
\gamma\end{array}$} \\
\hline & & & $\beta$ & $\chi$ & & & $\varepsilon$ & $\varphi$ & & \\
\hline \multicolumn{2}{|l|}{$t$} & $\alpha(t)$ & & & & & & & & $\gamma(\mathrm{t})$ \\
\hline \multirow{6}{*}{$t+1$} & sub-step 1 & $\alpha(t)$ & & & & & read value & & & $\gamma(\mathrm{t})$ \\
\hline & sub-step 2 & & compute & & compute & & & & compute & \\
\hline & sub-step 3 & & & & & & & compute & & \\
\hline & sub-step 4 & & & & & compute & & & & \\
\hline & sub-step 5 & & & compute & & & & & & \\
\hline & sub-step 6 & $\alpha(t+1)$ & & & & & & & & $\gamma(\mathrm{t}+1)$ \\
\hline
\end{tabular}

Fig. B.1. Graphical representation of the computational sequence (for Fig. 2(b)) implemented in the system dynamics environment.

The first sub-step uses the value of stocks $\alpha$ and $\gamma$ from the previous time step and the exogenous (historical) value of $\varepsilon$ (interpolated between the annual values). There is now information to calculate $\beta, \delta$, and $\eta$ in sub-step 2 (Eq. (B.1), (B.2) and (B.3)); all values are a function of time in integer steps, but for clarity these time steps are shown only for $\alpha_{\bmod }$ and $\gamma_{\bmod }$ :

$$
\begin{aligned}
\text { sub - step 2: } & \delta_{\text {mod }}=\alpha_{\text {mod }}(t) \cdot \frac{\delta_{\text {hist }}}{\alpha_{\text {hist }}}, \\
& \beta_{\text {mod }}=\alpha_{\text {mod }}(t) \cdot \frac{\beta_{\text {hist }}}{\alpha_{\text {hist }}}, \\
& \eta_{\text {mod }}=\gamma_{\bmod }(t) \cdot \frac{\eta_{\text {hist }}}{\gamma_{\text {hist }}}
\end{aligned}
$$

Sub-steps 3 to 6 (Eq. (B.4)-( B.7)) then follow to arrive at a new value for $\alpha$, the final result of time-step $t=$ $\mathrm{t}+1$.

$$
\begin{aligned}
& \text { sub - step 3: } \varphi_{\text {mod }}=\eta_{\text {mod }}(t) \cdot \frac{\varphi_{\text {hist }}}{\eta_{\text {hist }}} \\
& \text { sub - step 4: shortfall }{ }_{\bmod }=\left(\varepsilon_{\text {hist }}+\varphi_{\text {mod }}\right)-\delta_{\text {mod }} \\
& \text { sub - step 5: } \chi_{\text {mod }}=\text { prop }- \text { gain } \cdot \text { shortfall }{ }_{\bmod }+\beta_{\text {mod }} \\
& \text { sub - step 6: } \quad \alpha_{\text {mod }}(t+1)=\alpha_{\text {mod }}(t)+\chi_{\text {mod }}-\beta_{\text {mod }}
\end{aligned}
$$

At any point in time $\mathrm{t}$ for each infrastructure $\mathrm{j}, F C_{j}, C F C_{j}$ and $F C F_{j}$ are computed by 
Final version appeared as: SH. Roberts, CJ. Axon, BD. Foran, NH. Goddard, \& BS. Warr (2016). A Robust Data-driven Macro-socioeconomic-energy Model. Trans IChemE Part E: Sustainable Production and Consumption, in press, DOI: 10.1016/j.spc.2016.01.003.

$$
F C_{j}(t)=F C_{j}(0)+\sum_{t=1}^{t}\left(F C F_{j}(t)-C F C_{j}(t)\right)
$$

$C F C_{j}(t)=C F C_{-} \operatorname{coef}_{j}(t) \cdot F C_{j}(t)$, and

$F C F_{j}(t)=\mathrm{CFC}_{j}(t)+$ prop $_{-}$gain $_{j} \cdot$ shortfall $(t)$, respective ly.

Proportional gain is described in section 3.6 and Appendix E.

\section{Appendix C: Configurations of feedback methods for each product}

Empirically we have found that five configurations (Fig. C.1) are sufficient to reconcile differences between supply and demand for all the different distinct product outputs. We now discuss briefly how each configuration might be selected and applied to a particular economy. Appendix D lists the configurations used in the UK case study.

We start with the simplest configuration in Fig. C.1(a) in which supply is predominantly from imports rather than domestic output, so FC of the domestic industry is insignificant. Simply, as more is demanded, more is imported. An example distinct output would be coal where an economy has dwindling indigenous reserves. For the two destinations shown, these could be power generation (a part of utilities) and manufacturing.

The separate account of changes at the system boundary of the economy is the balance of payments (BoP). Whilst the principles we introduced in Fig. 1 depend only on proxy measures for goods, services, energy and so on, the monetary transactions of the BoP impose a requirement on a real economy that we must also consider. If Fig. C.1(a) is applied to coal, then the price of coal converts the energy content brought into the economy into the outgoing funds to pay for this import.

The configuration in Fig. C.1(b) is similar to the introduction in Fig. 2(b). Supply is output from $\mathrm{FC}_{1}$ alone (with no imports) and demand is by FC in other boxes. Here feedback changes investment to $\mathrm{FC}_{1}$ of the supply. An example is electricity when there are minimal imports via interconnectors with neighbouring countries. The supply box would be power generation and FC boxes for demand would be all buildings and other users of electricity.

In case Fig. C.1(c), supply is from both $\mathrm{FC}_{1}$ and imports and the demand is created by FC in other boxes. The feedback changes investment to $\mathrm{FC}_{1}$ of the supply, and its output is used to calculate imports. We are not saying that domestic output determines imports, but that we model imports by a coefficient applied linearly to output. This is justified empirically where this imports coefficient is smoothly varying over the historical period.

We develop this further in case Fig. C.1(d). The key feature of this configuration is that shortfall is calculated at the final supply of product $f_{4}$ (Fig. 4) with feedback implemented to change production of its predominant source product $q_{4}$. This configuration is necessary for each of the three larger industries. The point to note is that feedback is just to the predominant industry and its $\mathrm{FC}_{4}$, even though more than one industry contributes to final product $f_{4}$. Nevertheless this brings about the required upstream adjustments because simultaneous action of the three feedback paths over a few time steps ensures that the required levels of several products $p$ necessary to meet demand for several products $f$ are achieved.

The BoP has its own requirements for balance (Fig. C.1(e)). The question of how changes in the nontrade components of BoP (e.g. investment in equities abroad and borrowing from abroad) affect other areas of the financial economy is complex, encompassing investor confidence, exchange rates, monetary policy and interest rates amongst other factors. We leave as exogenous all but one of non-trade components of BoP to show effects of trade on non-trade.

All configurations incorporate a conservation principle, analogous to the conservation of mass and energy in physical processes. This is mirrored by the principle we work with here of accounting balance for each and all of the distinct outputs. 
Final version appeared as: SH. Roberts, CJ. Axon, BD. Foran, NH. Goddard, \& BS. Warr (2016). A Robust Data-driven Macro-socioeconomic-energy Model. Trans IChemE Part E: Sustainable Production and Consumption, in press, DOI: 10.1016/j.spc.2016.01.003.

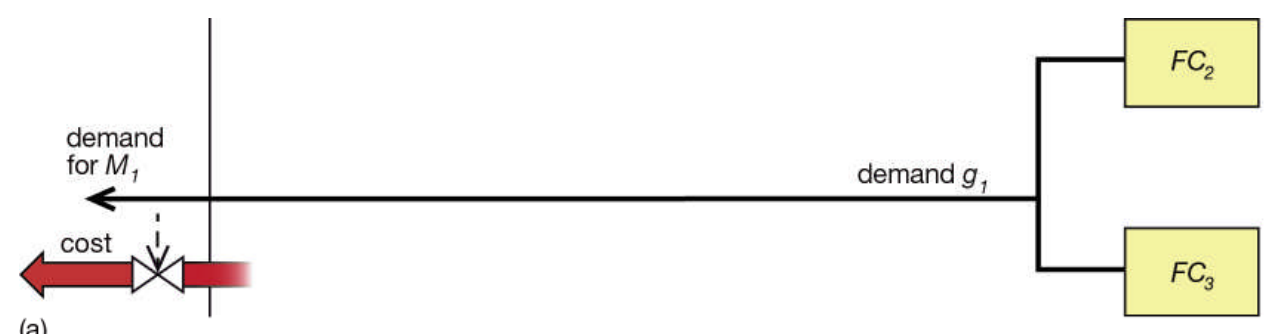

(a)

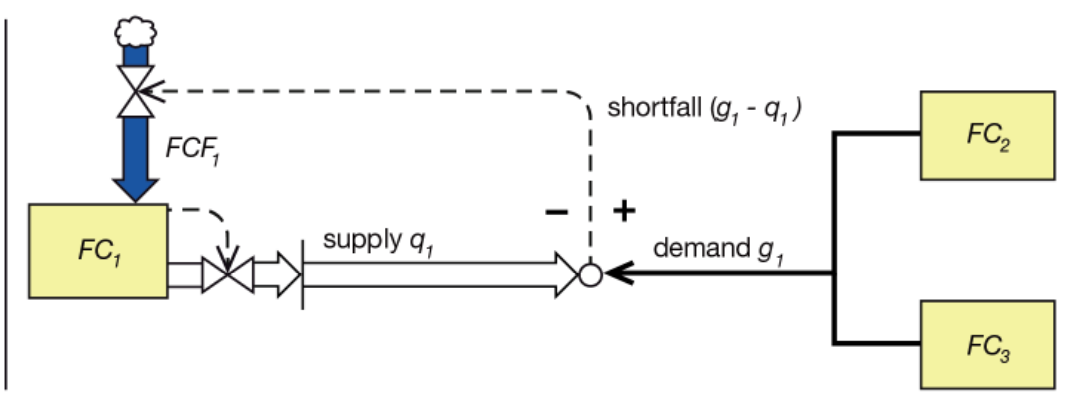

(b)

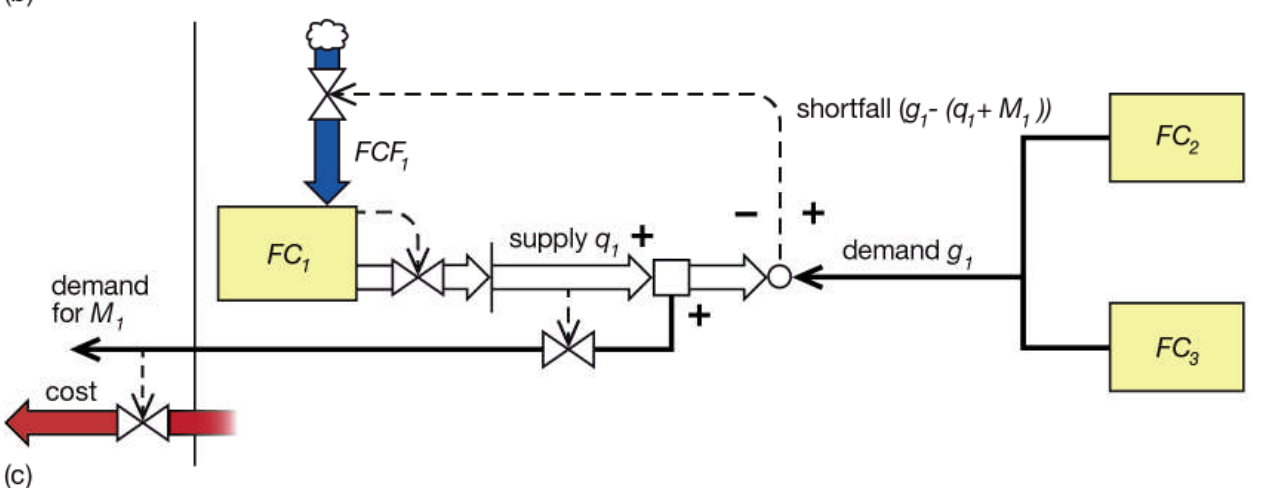

(c)

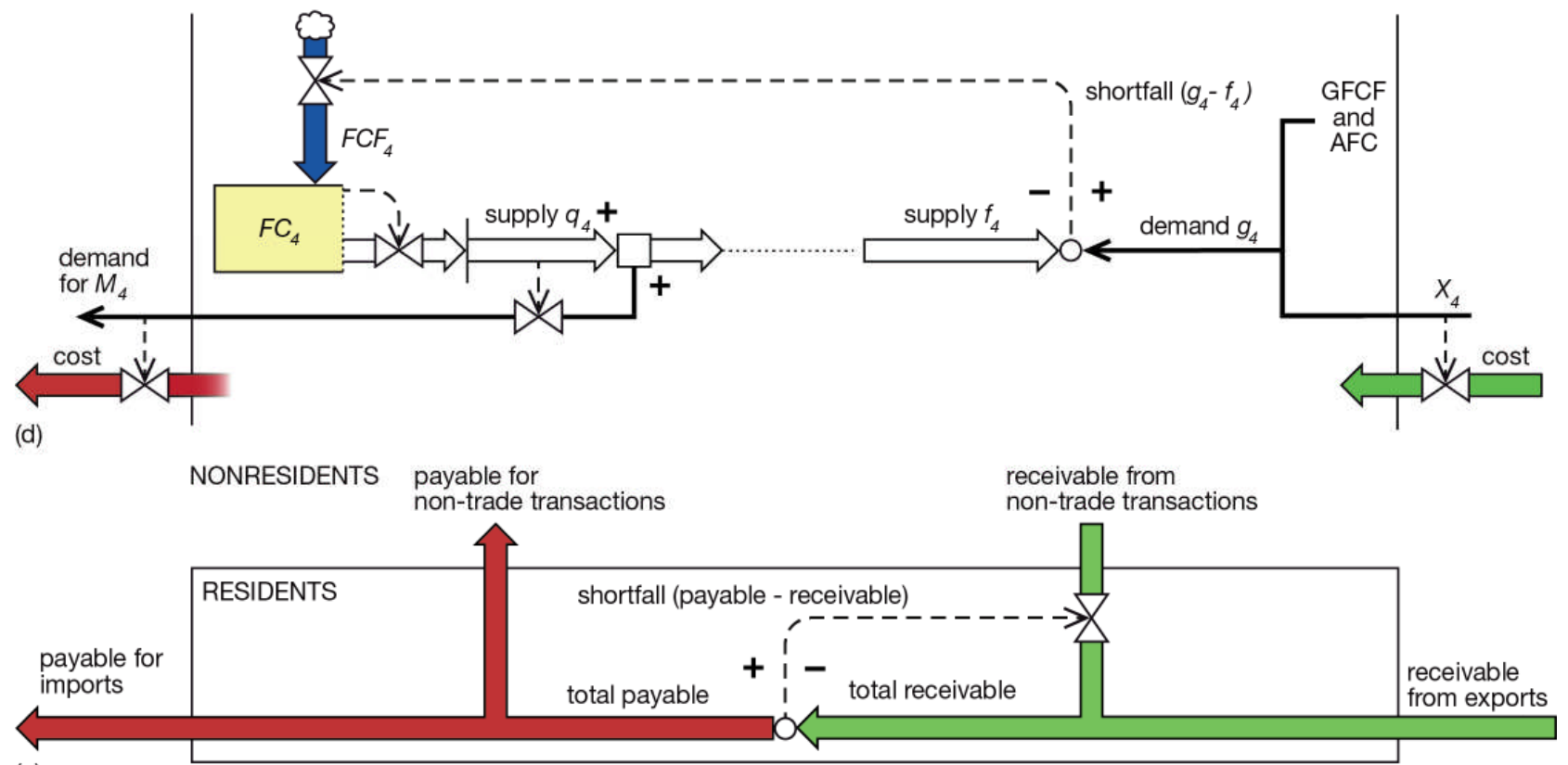

(e)

Fig. C.1. One simple case and four configurations of feedback control in which shortfall enables supply $q$ to meet demand $g$, or BoP to be balanced: (a) all supply from imports $\left(M_{l}\right)$; (b) all supply from domestic production by $F C_{l}$; (c) supply from a combination of production by $F C_{l}$ and imports, $M_{l}$; (d) supply evolves from $q$ to $f$ (see Fig. 4) and demand is not from other fixed capital but the sum of GFCF (gross fixed capital formation), AFC (actual final consumption) and exports, $X_{4}$; (e) feedback specific to BoP. 
Final version appeared as: SH. Roberts, CJ. Axon, BD. Foran, NH. Goddard, \& BS. Warr (2016). A Robust Data-driven Macro-socioeconomic-energy Model. Trans IChemE Part E: Sustainable Production and Consumption, in press, DOI: 10.1016/j.spc.2016.01.003.

\section{Appendix D: Preliminary steps to set up the 7see-GB model for the UK case study}

Four steps enable the model to run forwards from $t=0$ (the year 1990):

1. For each unique output, assign the configuration of feedback, selecting from Fig. C.1.

2. Calculate all the output, production and other coefficients from historical data.

3. For all the remaining outputs not set by feedback or coefficients, identify these as exogenous and set them equal to historical data.

4. For all FC, use only the initial values, these being the historical data at the start of the historical period.

There remain a small number of parameters which must be tuned (section 4 and Appendix E). The feedback configurations required are summarised in Table D.1. In Table D.2 we list many of the individual outputs used in the UK model together with the choice of appropriate feedback class from Table D.1.

Table D.1. Summary of the feedback configurations shown schematically in Fig. C.1. Supplies of type $q$ and $f$ are shown in Fig. 4. Demand of type $g$ shown in Fig. 5 and 6.

Reference to configurations in Fig. C.1 of how the shortfall achieves feedback

\begin{tabular}{|c|c|c|c|c|c|}
\hline & (a) & (b) & (c) & (d) & (e) \\
\hline Shortfall & (Not & \multicolumn{2}{|c|}{ demand $g$ LESS supply of type $q$} & demand $g$ LESS & total payable \\
\hline $\begin{array}{l}\text { Shortfall } \\
\text { determines: }\end{array}$ & $\begin{array}{l}\text { (All supply is } \\
\text { from imports) }\end{array}$ & $\begin{array}{l}\text { all supply from } \\
\text { domestic output }\end{array}$ & $\begin{array}{l}\text { supply from domestic } \\
\text { output and imports }\end{array}$ & $\begin{array}{l}\text { supply from } \\
\text { domestic output and } \\
\text { imports }\end{array}$ & $\begin{array}{l}\text { a component } \\
\text { of non-trade }\end{array}$ \\
\hline
\end{tabular}

Table D.2. A list of the major outputs in the 7see-GB model and the choice of feedback control selected.

\begin{tabular}{|c|c|c|c|c|c|c|}
\hline \multirow[t]{2}{*}{ Output } & \multicolumn{5}{|c|}{$\begin{array}{l}\text { Configurations (Table D.1) of how shortfall } \\
\text { achieves feedback }\end{array}$} & \multirow[t]{2}{*}{$\begin{array}{l}\text { Notes as appropriate about FC and } \\
\text { other aspects of the output }\end{array}$} \\
\hline & (a) & (b) & (c) & (d) & (e) & \\
\hline agri & $\checkmark$ & & & & & FCF exogenous \\
\hline extr, FC alone & & & & & & FCF exogenous \\
\hline extr coal & $\checkmark$ & & & & & \\
\hline extr oil & $\checkmark$ & & & & & \\
\hline extr gas & $\checkmark$ & & & & & \\
\hline util without elec.* & & & & & & FCF exogenous \\
\hline util elec. from gas & & $\checkmark$ & & & & \\
\hline util elec. not from gas & & & & & & FCF exogenous \\
\hline manu & & & & $\checkmark$ & & \\
\hline manu imports & & & $\checkmark$ & & & exports exogenous \\
\hline manu petroleum products & $\checkmark$ & & & & & domestic refinery capacity exogenous \\
\hline cnstr & & & & $\checkmark$ & & \\
\hline $\operatorname{serv} L R$ & & & & $\checkmark$ & & \\
\hline serv $L R$ imports & & & $\checkmark$ & & & exports exogenous \\
\hline balance of payments $* *$ & & & & & $\checkmark$ & \\
\hline
\end{tabular}

* util for distribution of electricity, gas and water; electricity generation handled separately.

** used to achieve balance is "investment into the UK for debt securities" (mainly corporate and Government bonds)

(IMF, 2011; ONS, 2012c). 
Final version appeared as: SH. Roberts, CJ. Axon, BD. Foran, NH. Goddard, \& BS. Warr (2016). A Robust Data-driven Macro-socioeconomic-energy Model. Trans IChemE Part E: Sustainable Production and Consumption, in press, DOI: 10.1016/j.spc.2016.01.003.

Other settings of outputs:

- actual final consumption: exogenous,

- $d w l g$ : FCF exogenous,

- transport: for road transportation, historical data for new registrations, typical vehicle life and average vehicle travel; exogenous for other transportation,

- jobs: the economically active population is exogenous.

\section{Appendix E: Feedback setting for individual data outputs}

The list of individual outputs in Appendix D has many instances of implementing feedback. Only three cases need configuring and these are of the form of Fig. C.1(d) as applied to the manufacturing, construction, and service industries.

We optimise the values of their proportional gains by examining the dynamic behaviour of their model-generated FCF in detail at the time-step resolution of the model (Fig. E.1). For each of the 16 sub-year steps, the annualised historical data is held constant, giving the staircase profiles. Given the potential for dynamic instability of positive feedback, we temporarily disconnect the GFCF path while optimising the proportional gain values. The disconnection is done by setting the final demand of GFCF to historical values for each of these industries.

The historical FCF for manufacturing (Fig. E.1(a)) is distorted by an exceptional event in $2005^{2}$. There is a matching reduction in historical FCF for service industry (Fig. E.1(c)). The optimum proportional gain for manufacturing is set to 0.20 . The higher value of 1.00 responds too sharply in 2004 which might lead to oscillations once the GFCF path is reconnected.

For construction (Fig. E.1(b)), the optimum proportional gain is 0.1 which follows the historical data well. The value of 0.02 is too low because the modelled flow FCF is too high, while the higher value of 1.0 gives rise to overshoot in 1991 and 2010.

For the service industry (Fig. E.1(c)), the optimum proportional gain is chosen as 3.0 because the modelled flow FCF tracks the stepped form of the historical data with a rapid sub-year settling time at each annual step. The higher gain of 10 doesn't cause oscillations, as for manufacturing and construction (not shown here), but causes excessive overshoot at many annual steps.

2 In April 2005 British Nuclear Fuels plc (BNFL) transferred to the Nuclear Decommissioning Authority (NDA) the decommissioning liabilities for nuclear reactors that were reaching the ends of their productive lives. BNFL is classified as a public corporation in the National Accounts and the NDA as central government. The transfer value of $-£ 15.6$ billion (negative for a liability) crossed the industry boundary (ONS, 2006). 
Final version appeared as: SH. Roberts, CJ. Axon, BD. Foran, NH. Goddard, \& BS. Warr (2016). A Robust Data-driven Macro-socioeconomic-energy Model. Trans IChemE Part E: Sustainable Production and Consumption, in press, DOI: 10.1016/j.spc.2016.01.003.
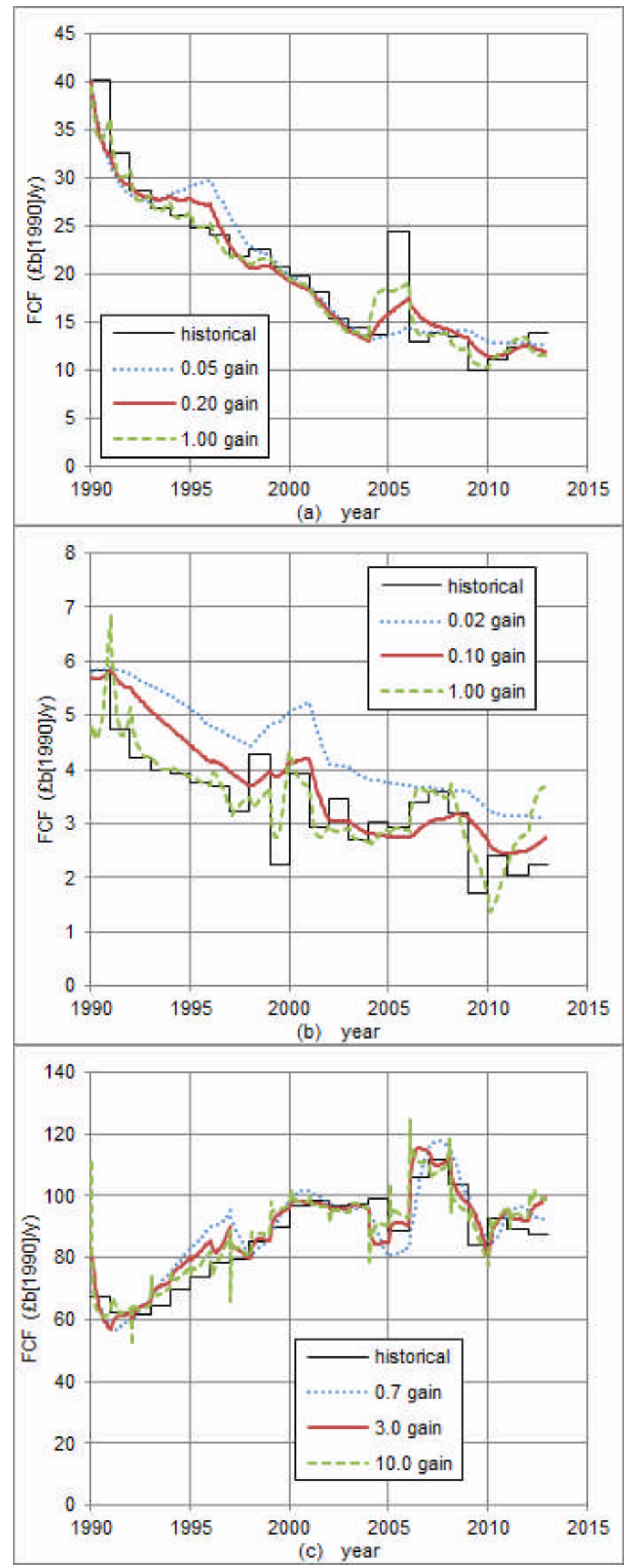
Final version appeared as: SH. Roberts, CJ. Axon, BD. Foran, NH. Goddard, \& BS. Warr (2016). A Robust Data-driven Macro-socioeconomic-energy Model. Trans IChemE Part E: Sustainable Production and Consumption, in press, DOI: 10.1016/j.spc.2016.01.003.

Fig. E.1. The performance of feedback at the model time-step resolution (16 steps per year) is for flows FCF of (a) manufacturing, (b) construction, (c) service industry. The GFCF components of their final demand are constrained to historical values. Data sources: ONS (2014a) with extrapolation pre-1997 fitted to total GFCF (ONS, 2012a).

Finding the values of proportional gain that keep the model stable is a minimum step in being able to go on to using the model for future scenarios. The success in regenerating historical data through feedback loops cannot be presumed and must be checked for every country-specific model. An example of historical data where this methodology might fail is if annual-quantised historical data includes large (positive and negative) changes frequently from year to year i.e. the underlying data is unstable and perhaps uncertain. 